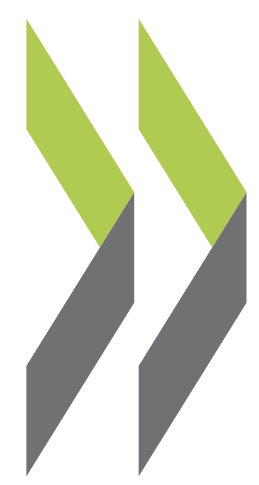

OECD Economics Department Working Papers No. 481

Balancing Health Care

Quality and Cost

Containment: The Case of

\section{Alexandra Bibbee,}

Flavio Padrini

\title{
Norway
}


Organisation de Coopération et de Développement Economiques

Organisation for Economic Co-operation and Development

17-Feb-2006

ECONOMICS DEPARTMENT

English - Or. English

BALANCING HEALTH CARE QUALITY AND COST CONTAINMENT: THE CASE OF NORWAY

ECONOMICS DEPARTMENT WORKING PAPER No. 481

by

Alexandra Bibbee and Flavio Padrini

All Economics Department Working Papers are now available through OECD's Internet Web site at www.oecd.org/eco/

JT00201240

Document complet disponible sur OLIS dans son format d'origine

Complete document available on OLIS in its original format 


\section{Abstract \\ Balancing health care quality and cost containment: the case of Norway}

In recent years, a series of wide-ranging reforms designed to make greater use of market mechanisms has succeeded in eliminating shortages, raising efficiency and improving citizen satisfaction. Nevertheless, spending accelerated after the reforms, and per capita spending on health is now one of the highest in the OECD. Centralisation of hospital ownership may have increased political influence, encouraging spending that cannot be justified on cost-benefit grounds. Co-payments by patients are modest, and the background of swelling oil wealth may have sapped willingness to control costs. Diagnosis related group (DRG) procedures are arguably too well-remunerated in some areas, leading to supply-driven interventions, while their absence in others (e.g. psychiatry) may have resulted in sub-optimal supply. Generalist doctors have a gatekeeper role, but are said to over-refer patients to hospitals. Although cost controlling mechanisms exist in Norway, they are too often sidestepped by pressure by citizens on politicians to approve new drugs and treatments. Thus, future health reforms in Norway should concentrate on value for money.

This paper relates to the 2005 OECD Economic Survey of Norway (www.oecd.org/eco/survey/norway).

JEL classification: I10, I11, I18

Key words: Norway, health care sector reform, activity based financing, primary care, specialized care, hospitals, pharmaceuticals, long term care, health care human resources

\section{Résumé}

\section{Trouver l'équilibre entre qualité des soins et maîtrise des coûts: le cas de la Norvège}

Ces dernières années, une série de réformes de grande ampleur visant à davantage utiliser les mécanismes de marché ont permis d'éliminer les files d'attentes, d'accroître l'efficacité du système de santé et d'améliorer la satisfaction des citoyens. Néanmoins, les dépenses ont accéléré, conduisant la Norvège à un des niveaux les plus élevés des pays de l'OCDE en terme de dépenses de santé par habitant. Le transfert de la propriété des hôpitaux aux administrations centrales a peut-être permis de laisser la place aux pressions politiques et encouragé les dépenses qui ne peuvent se justifier du strict point de vue de l'efficacité économique. La participation financière des patients est peu élevée et l'accroissement de la richesse pétrolière a sans nul doute nui à la volonté de maîtriser les coûts. Le système des groupes homogènes de malades aboutit probablement à des rémunérations excessives dans certains domaines, entraînant des interventions induites par l'offre, alors que l'absence de groupes de ce type dans d'autres domaines (comme la psychiatrie) a donné lieu à une offre insuffisante. Les généralistes jouent un rôle de filtrage, mais auraient tendance à trop orienter les malades vers les hôpitaux. Bien que des mécanismes de contrôle des coûts existent en Norvège, ceux-ci sont trop souvent court-circuités, les citoyens exerçant des pressions sur les élus pour approuver de nouveaux médicaments et traitements. Ainsi, les futures réformes du système de santé en Norvège devraient davantage se concentrer sur les aspects efficacité coûts.

Ce document de travail se rapporte à l'Etude économique de la Norvège 2005 (www.oecd.org/eco/etudes/norvege).

Classification JEL : I10, I11, I18

Mots clés : Norvège, réforme des systèmes de santé, financement par activité, soins spécialisés, secteur hospitalier, soins de ville, gestion des ressources humaines dans le secteur de la santé, secteur pharmaceutique.

Copyright OECD, 2006

Application for permission to reproduce or translate all, or part of, this material should be made to: Head of Publications Service, OECD, 2 rue André Pascal, 75775 Paris Cedex 16, France. 


\section{TABLE OF CONTENTS}

\section{BALANCING HEALTH CARE QUALITY AND COST CONTAINMENT: THE CASE OF NORWAY 5}

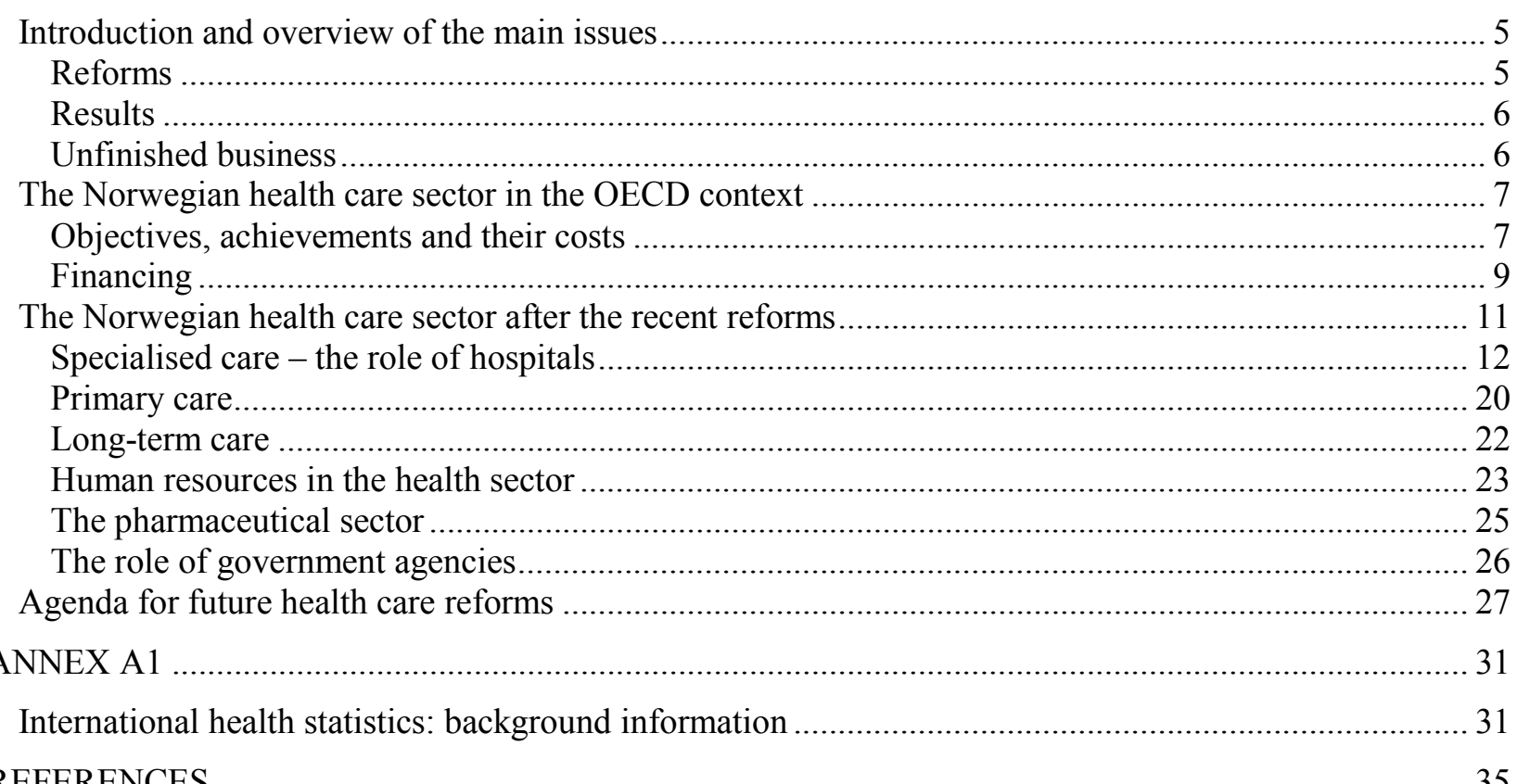

\section{Tables}

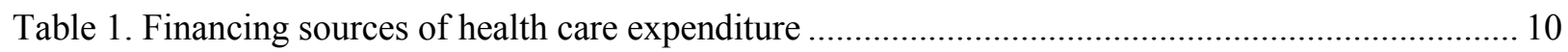

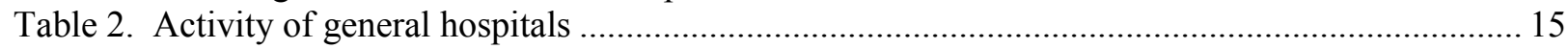

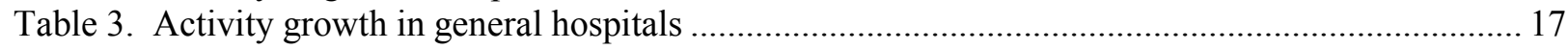

Table 4. Municipal expenditure for primary care per inhabitant......................................................... 21

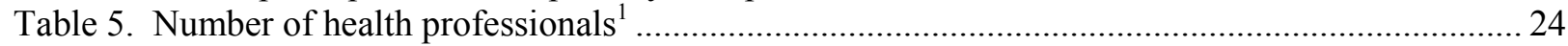

\section{Figures}

Figure 1. Total health care expenditure in OECD countries ................................................................. 8

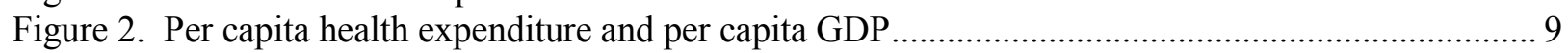

Figure 3. Total expenditure on personal health care by function ..................................................... 12

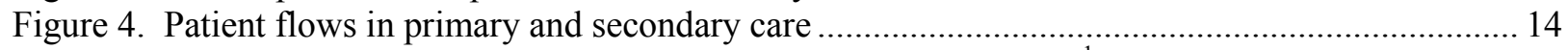

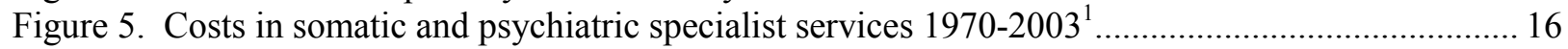

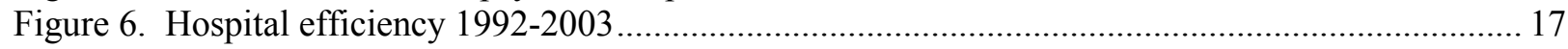

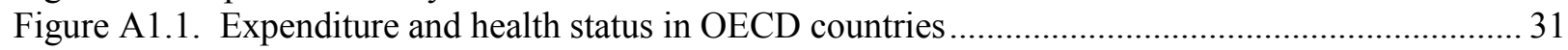

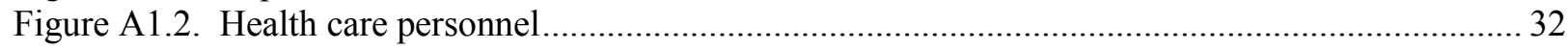

Figure A1.3. Acute-care and long-term-care beds ........................................................................... 33

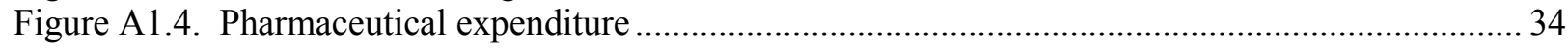




\section{$\mathrm{ECO} / \mathrm{WKP}(2006) 9$}

\section{Boxes}

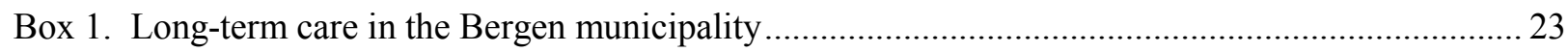

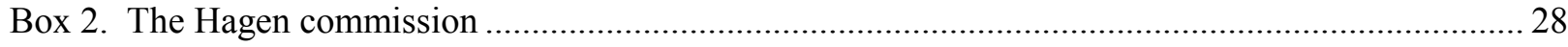

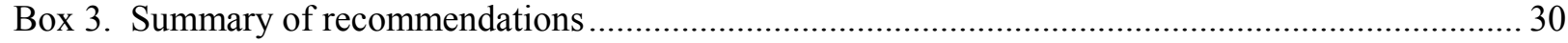


ECO/WKP(2006)9

\title{
BALANCING HEALTH CARE QUALITY AND COST CONTAINMENT: THE CASE OF NORWAY ${ }^{1}$
}

\author{
by Alexandra Bibbee and Flavio Padrini
}

\section{Introduction and overview of the main issues}

1. The Norwegian health care sector faces the same drivers as in other countries, namely that both the demand for, and the potential to supply medical treatments and services rise with income, newer medical technologies are not necessarily cost-saving, and lengthening life expectancy is likely to put continuing upward pressure on demand. The 1998 OECD Economic Survey of Norway identified three major challenges for the Norwegian health care sector: $i$ ) capacity shortages as suggested by long waiting lists, and human resource shortages in the health professions; ii) balancing the need for cost-effectiveness and the ambition of maintaining comprehensive health care services countrywide; and iii) risk of expenditure rise in the future. This paper describes the main reform measures, attempts to identify their impact on the Norwegian health care sector focusing on developments since the mid-1990s and makes recommendations for further improvements.

\section{Reforms}

2. Since the late 1990s, Norway has implemented an impressive amount of reforms aimed at greater efficiency of delivery of medical services, in part by allowing a greater role for market focus, while maintaining and where possible strengthening, quality and equity. They include the following:

- Measures to strengthen the gatekeeper role of general practitioners as well as to improve their services have been introduced in primary care.

- In specialised care, activity-based financing is being expanded. A major organisational reform of the hospital sector has also been implemented.

- Ambitious objectives have been set centrally for long-term care and municipalities are currently making major efforts to achieve them.

1. Alexandra Bibbee and Flavio Padrini are, respectively, members of Country Studies II Division and the Structural Policy Analysis Division of the Economics Department. This paper is based on work originally prepared for the OECD Economic Survey of Norway 2005 published under the responsibility of the Economic Development and Review Committee. The authors are indebted to Nick Vanston and Heidi Langaas for valuable comments, Sylvie Toly for statistical assistance, and to Christina Quaglio, Hervé Bource and Chrystyna Harpluk for secretarial assistance. 
- Liberalisation has been unfolding in the pharmaceutical sector and measures to contain public expenditure on drugs have been enforced.

- Programmes have been devised to relieve shortages of human resources in the health professions.

\section{Results}

3. Both supply of services and responsiveness have improved following the implementation of the reforms:

- Activity of both hospitals and private physicians has increased.

- The technical efficiency of public hospitals seems to have improved. Waiting times have been reduced both in primary and specialised care.

- More pharmacies are available in urban areas without impairing supply in remote areas, and they stay open longer hours.

- Human resource shortages are not a major matter of concern anymore, at least in highly populated areas.

- The majority of the population seems satisfied with the way their health care sector is run.

\section{Unfinished business}

4. The measures implemented, however, have not fully solved some long-standing problems and might have increased the urgency to solve others.

- Spending -- especially public spending -- has continued to rise robustly despite the reforms, resulting in per capita health care expenditure which is one of the highest in the OECD.

- Questions are arising as to whether activity-based financing is providing the right incentives for a socially optimal allocation of financial resources, and whether more budgetary discipline needs to be imposed.

- Expost expenditures are almost invariably higher than what is considered socially desirable ex ante, especially in specialised care.

- The cost-effectiveness of many treatments is uncertain, thus hardly justifying their rising supply, whereas activity in other areas prioritised by the central government -- like psychiatric care -- has been lower than expected.

- Despite higher spending, geographical variability in the quantity and quality of services is still a matter of concern for the authorities.

- Competition in the hospital sector as well as in the retail and wholesale pharmaceutical market is proving difficult to augment. As a result, one important incentive to greater efficiency is missing. 


\section{The Norwegian health care sector in the OECD context}

\section{Objectives, achievements and their costs}

5. Norway has sweeping objectives for its health care sector. Health care provision is based on the universal principle. All residents in Norway are publicly insured. No major health risk is excluded from the public insurance scheme and all treatments that are scientifically documented to provide effective results are covered. $^{2}$

6. The 1999 Act on Patient Rights and the 2001 Act on Health Enterprises reinstated equity principles in the health care sector implying an equal use of health care services for individuals with equal needs regardless of income, age, education, gender, ethnic background and place of residence. Dispersion of the population makes this last condition hard to attain. This is particularly the case for services provided by self-employed medical practitioners -- general practitioners (GPs), specialised physicians with private ambulatory patients and dentists -- for whom working in low-density areas is less profitable than in urban areas. Nonetheless, the Norwegian population is broadly satisfied with its health care sector. Indeed, a 2003 survey from Statistics Norway (2004) shows that around $60 \%$ of the interviewed persons were satisfied with the way health care is run in Norway. ${ }^{3}$

7. And in fact, the health status of Norwegians is good, though not outstandingly so. Life expectancy at birth and at age 65 is above average, infant mortality is the sixth lowest among OECD countries, the incidence of obesity is very low, and Norway scores well on other measures -- though not disproportionately so, given the level of spending. Annex A1 gives details of health parameters, with emphasis on international comparisons.

8. Health care expenditure ${ }^{4}$ as a share of GDP remained broadly stable until the end of the 1990s but started to grow thereafter and was $9 \frac{1}{2}$ per cent in 2002, one percentage point higher than the OECD average (Figure 1). ${ }^{5}$ In per capita terms, health care spending in Norway is the third highest in the OECD, after the United States and Switzerland. To some extent, this could reflect the empirical relationship between per capita GDP and per capita health spending, the Baumol effect, resulting from a high relative price of health expenditure (Figure 2). Nevertheless, per capita expenditure is more than $50 \%$ above the OECD average, and also well above levels in other Nordic countries.

2. The Department of Health and Social Affairs is responsible for coordinating the process leading to the identification of treatments to be covered. Very few treatments are excluded from the public insurance scheme, examples being cosmetic surgery, acupuncture and homeopathy, and sterilisation for non-medical reasons. However, for the latter two a recent act establishes a register of practitioners. The majority of the population needs to pay for dental care.

3. A 1999 European Commission Eurobarometer survey suggested that $53 \%$ of the EU-15 population were satisfied with their health care systems, a lower percentage than in Norway. However, comparison of the surveys' results needs to be treated with care as the survey methods used by Statistics Norway and the European Commission might not be comparable. Moreover, the year of the two surveys is different. Finally, the results could be affected by different expectations of the population regarding health care services.

4. Total expenditure on health includes curative, preventive, long term, nursing, and hospice care as well as public health programmes.

5. Health care expenditure was $12 \%$ of Mainland GDP in 2002, the second highest in the OECD. It should be noted that health spending jumped significantly in 2001 when the general practioner scheme was included in health spending. 
Figure 1. Total health care expenditure in OECD countries As a percentage of GDP
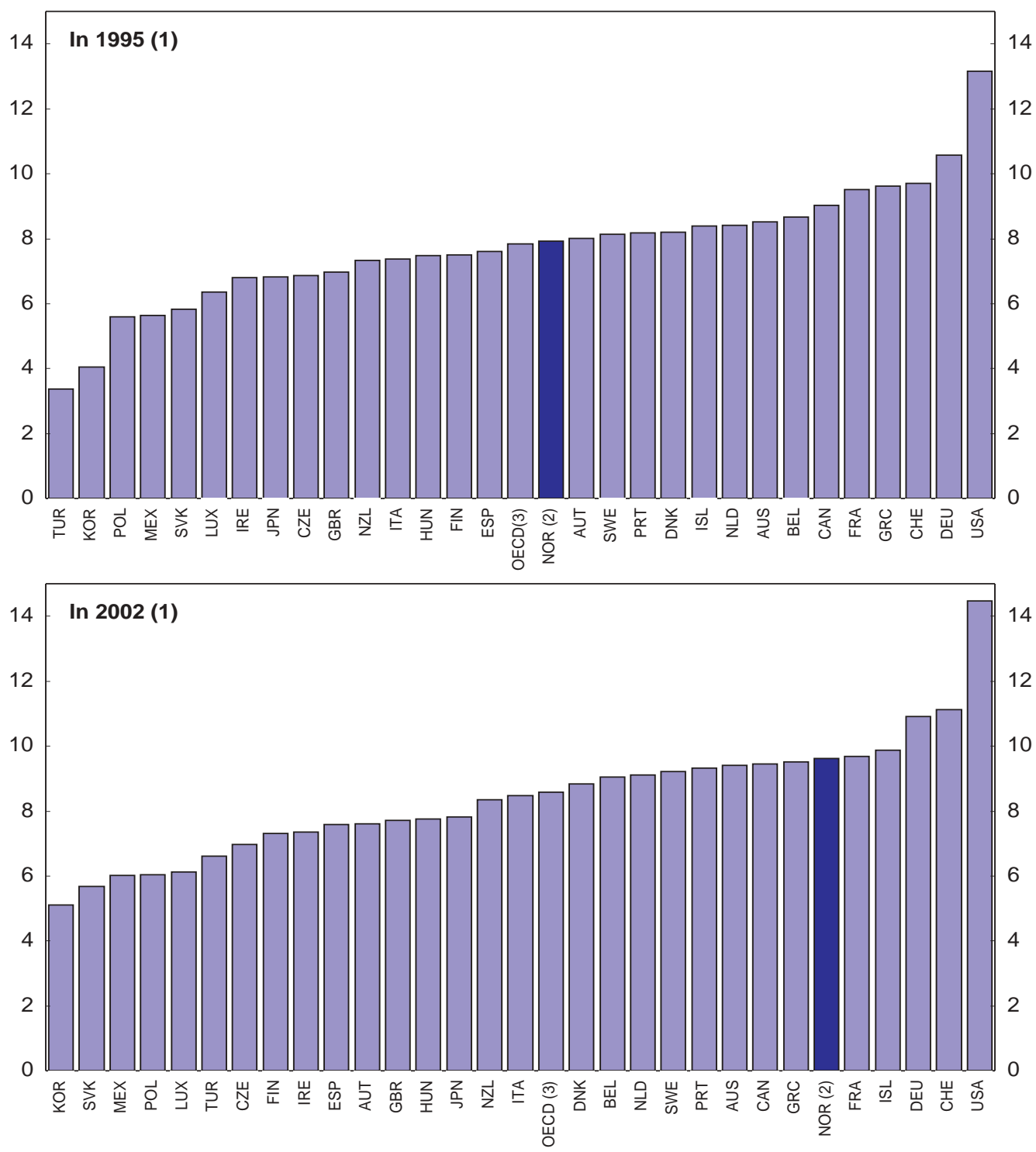

1. Or nearest year available.

2. As a percentage of total GDP. Considering mainland GDP, the ratio was 9.3 and 12.0 respectively in 1995 and 2002.

3. Unweighted average. Includes all available countries at the relevant point in time.

Source: OECD Health Data, 2004; OECD Economic Outlook 76 database. 
Figure 2. Per capita health expenditure and per capita GDP

In USD PPP, $2002^{1}$

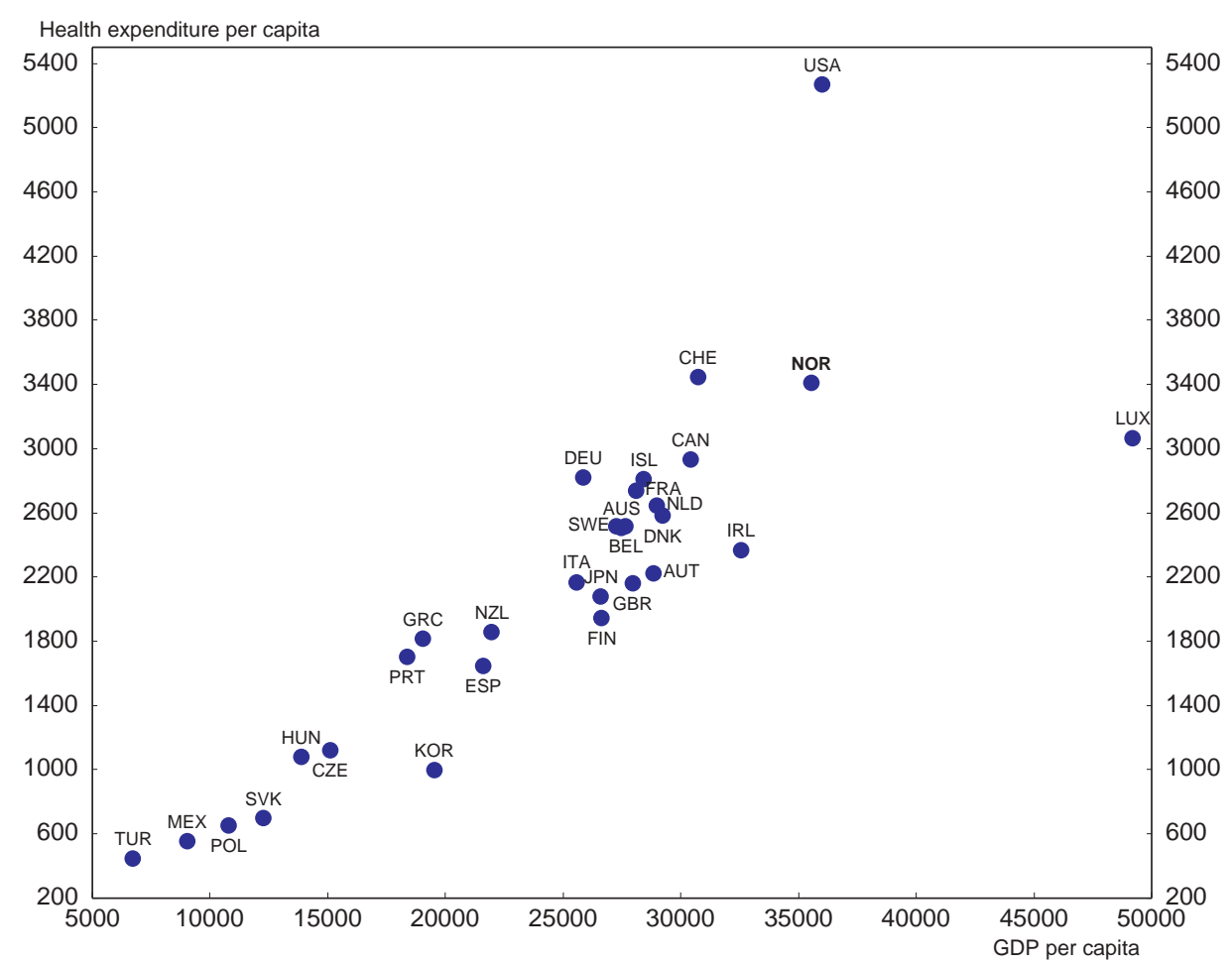

1. 2001 for Australia and Japan; 2000 for Turkey.

Source: OECD Health Data, 2004.

9. As off-shore GDP is expected to shrink and the share of the elderly to rise during the next decades, maintaining far-reaching objectives for the health care sector will prove increasingly burdensome in the medium-to-long term. A projection exercise, carried out by national experts and co-ordinated by the OECD, shows that health care expenditure as a share of total GDP could grow by up to $51 / 4$ percentage points in Norway during the first half of the current century. This compares with the rise of $3 \frac{1}{4}$ percentage points of GDP expected on average by a number of OECD countries. ${ }^{6}$

\section{Financing}

10. The public sector finances around $85 \%$ of health care (Table 1) mainly through general taxation, compared with an OECD average of $74 \%$. Health spending by local governments is mostly financed via central government block grants. Moreover, the final responsibility regarding health policy, public health and the provision of health care services rests with the Ministry of Health (see Ministry of Health and Social affaires, n.d. undated, for the fields of responsibility of the Ministry). During the past few years, the direct financial involvement of the central government rose as the state took over hospital ownership from

6. Besides Norway, health care projections are available for Austria, Belgium, the Czech Republic, Denmark, Finland, France, Ireland, Italy, Japan, the Netherlands, New Zealand, Sweden and the United Kingdom. For Norway, future health care expenses per capita were indexed to labour productivity in Mainland GDP and on the inflation rate rather than on total GDP per capita as in the other OECD countries. Since projections by country did not share identical assumptions, the international comparisons should be treated with care. 
counties (see section on specialised care below) and made increased use of earmarked grants for municipalities, for example in implementing the psychiatric-health-care-strengthening plan launched in 1999.

Table 1. Financing sources of health care expenditure As share of total health expenditure, in 2002

\begin{tabular}{|c|c|c|c|c|c|}
\hline & $\begin{array}{c}\text { Total } \\
\text { public }\end{array}$ & $\begin{array}{c}\text { Private } \\
\text { health } \\
\text { insurance }\end{array}$ & $\begin{array}{c}\text { Out-of } \\
\text { pocket } \\
\text { spending }\end{array}$ & $\begin{array}{c}\text { Other } \\
\text { private } \\
\text { spending }\end{array}$ & $\begin{array}{c}\text { Total } \\
\text { private }\end{array}$ \\
\hline Australia & .. & .. & .. & .. & .. \\
\hline Austria & 69.9 & 7.4 & 17.5 & 5.2 & 30.1 \\
\hline Belgium & 71.2 & .. & .. & .. & 28.8 \\
\hline Canada & 69.9 & 12.7 & 15.2 & 2.3 & 30.1 \\
\hline Czech Republic & 91.4 & .. & 8.6 & .. & 8.6 \\
\hline Denmark & 82.9 & 1.6 & 15.3 & 0.0 & 17.1 \\
\hline Finland & 75.7 & 2.4 & 20.0 & 1.9 & 24.3 \\
\hline France & 76.0 & 13.2 & 9.8 & 1.0 & 24.0 \\
\hline Germany & 78.5 & 8.6 & 10.4 & 2.6 & 21.5 \\
\hline Greece & 52.9 & .. & .. & .. & 47.1 \\
\hline Hungary & 70.2 & 0.4 & 26.3 & 3.1 & 29.8 \\
\hline Iceland & 84.0 & .. & 16.0 & .. & 16.0 \\
\hline Ireland & 75.2 & 5.4 & 13.2 & 6.3 & 24.8 \\
\hline Italy & 75.6 & 0.9 & 20.3 & 3.2 & 24.4 \\
\hline Japan & .. & .. & .. & .. & .. \\
\hline Korea & 52.1 & 2.0 & 39.6 & 6.3 & 47.9 \\
\hline Luxembourg & 85.4 & 1.4 & 11.9 & 1.4 & 14.6 \\
\hline Mexico & 44.9 & 3.0 & 52.1 & 0.0 & 55.1 \\
\hline Netherlands & .. & .. & .. & .. & .. \\
\hline New Zealand & 77.9 & 5.7 & 16.1 & 0.3 & 22.1 \\
\hline Norway & 83.5 & .. & 16.1 & 0.5 & 16.5 \\
\hline Poland & 72.4 & .. & 27.6 & .. & 27.6 \\
\hline Portugal & 70.6 & .. & .. & .. & 29.4 \\
\hline Slovak Republic & 89.1 & .. & 10.9 & .. & 10.9 \\
\hline Spain & 71.4 & 4.1 & 23.6 & 0.9 & 28.6 \\
\hline Sweden & 85.3 & .. & .. & .. & 14.7 \\
\hline Switzerland & 57.9 & 9.6 & 31.5 & 1.0 & 42.1 \\
\hline Turkey & .. & .. & .. & .. & .. \\
\hline United Kingdom & 83.4 & .. & .. & .. & 16.6 \\
\hline United States & 44.9 & 36.2 & 14.0 & 4.9 & 55.1 \\
\hline $\mathrm{OECD}^{1}$ & 72.8 & 7.2 & 19.8 & 2.4 & 27.2 \\
\hline
\end{tabular}

1. Unweighted average.

Source: OECD Health Data 2004. 
11. Out-of-pocket payments represent around $16 \%$ of total health care expenditure while the role of private insurance is negligible. Two annual ceilings for out-of-pocket payments are established every year by the parliament and they are quite low. In 2005, the first ceiling was to NOK 1,585 (around EUR 195) including inter alia prescription drugs, hospital outpatient care, primary and secondary ambulatory care, and transport costs to health facilities. Almost a quarter of Norwegians reach the ceiling. The second ceiling amounts to NOK 3500 in 2005 (around EUR 425) and comprises physiotherapy treatments, participations in programmes for treatments abroad, some dental treatment and stays at rehabilitation institutions. A number of exemptions for selected services within the ceiling are in place for example for the elderly with a minimum pension, some important drugs and medical equipment. Hospital inpatient care — including same-day treatments — is free for the patients. ${ }^{7}$

12. Since the mid-1990's, the input mix in the health care sector has changed considerably. The number of nurses has risen faster than that of physicians (Figure A2), to become one of the highest in the OECD per capita. The level of per capita acute beds remains below the OECD median while long-termcare beds per capita are among the highest in the OECD (Figure A3). Finally, despite remaining low as a percentage of $G D P$ relative to other OECD countries, pharmaceutical expenditure has visibly increased in per capita terms since the mid-1990s and is now around the OECD median (Figure A4). These changes have tended to raise costs.

\section{The Norwegian health care sector after the recent reforms}

13. Since the mid-1990's Norway has undertaken a series of reforms ranging across all fields of the health care sector. This section focuses on how they have affected performances. ${ }^{8}$ Special attention is devoted to the hospital sector whose activities represent more than half of total spending on personal health care (including spending on nursing homes, accounting for about one-third of "in-patient expenditure") (Figure 3). ${ }^{9}$

7. A plan to explore whether a system of out-of-pocket payments could be established according to treatment priority, has been set aside as a survey of physician practices revealed that there is no broad consensus on illness and treatment priorities.

8. For a description and analysis of the Norwegian health care sector in the second half of the 1990s, see OECD (1998) and European Observatory on Health Care Systems (2000).

9. The Norwegian authorities are also putting increasing emphasis on preventive care of non-communicable diseases, e.g. smoking prevention, nutrition awareness campaigns and incentives for participation in sports. The authorities recognise that identifying expected costs and benefits of these measures is difficult in practice. There is nonetheless a plan to use health impact assessments, including also an economic assessment, as a tool to evaluate the usefulness of preventive measures. 
Figure 3. Total expenditure on personal health care by function As a percentage of total expenditure in 2001

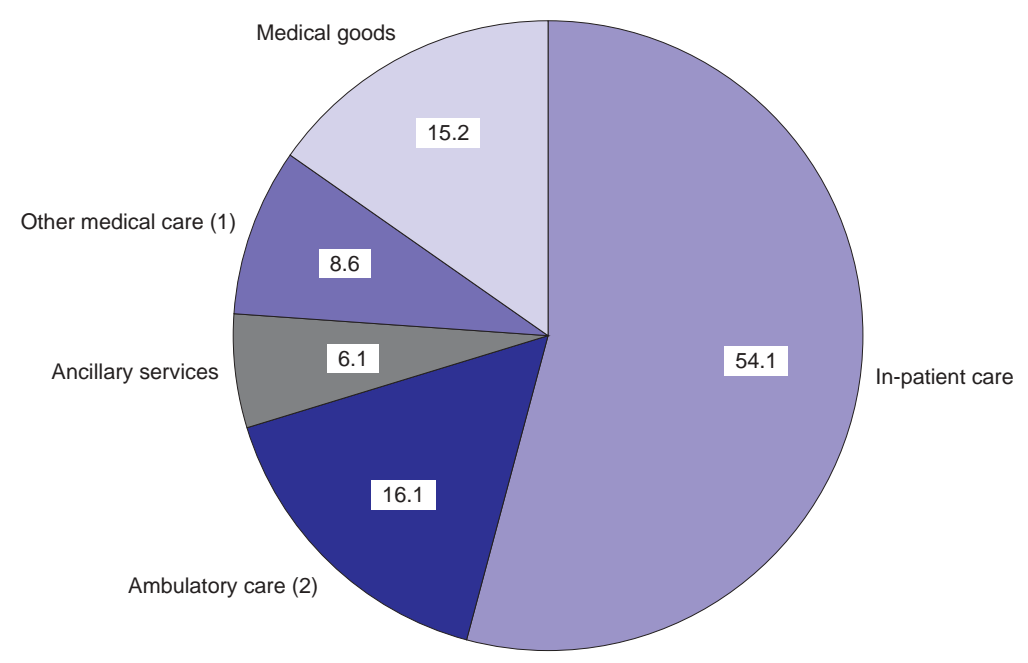

1. Includes day treatments and home care.

2. Includes medical services delivered to patients in physician private offices, hospital out-patient centres or ambulatory care centres.

Source: OECD Health Data 2004.

\section{Specialised care - the role of hospitals}

14. The bulk of specialised health care, especially inpatient care, is performed by public hospitals. ${ }^{10}$ A few private clinics offering outpatient and inpatient care are operating, and specialised ambulatory care can also be supplied by self-employed physicians. ${ }^{11}$

\section{Recent wide-ranging reforms}

15. In July 1997, the government substituted part of the block-grant financing system for general hospitals with a new system based on activity. Reimbursement to general hospitals for inpatient care encompasses a block grant and an activity-based component, the latter being calculated on the basis of the number of patients treated and of the Diagnosis Related Group (DRG) reference system (Hagen and Kaarboe, 2003). The reimbursement is based on average rather than marginal costs; the latter may be lower because of scale economies.

10. Specialised health care in Norway is expected to perform a number of tasks. The main ones are to provide specialised treatments to patients, make sure that their rights are fulfilled as laid out in legislation, involve patients in their own treatment and co-operate with primary care. Other tasks are to educate towards good health practice patients and their relatives, to train health professionals and to perform research, treatment evaluation and introduce innovation.

11. Both public and private hospitals need permission from the Ministry of Health to start their operations. 
16. The activity-based component of inpatient care financing has risen erratically over time, passing from $30 \%$ of the total initially to $60 \%$ presently. ${ }^{12}$ No out-of-pocket payment is required. For hospital outpatient care, activity-based financing -- which remains at $40 \%$-- is based on a fee-for-service method and part of this component is paid out-of-pocket by patients while the rest is reimbursed by the National Insurance Scheme (NIS). Psychiatric and geriatrics rehabilitation hospitals continue to be financed through block grants.

17. In 1999, the Act on Patient Rights introduced free choice of all public hospitals by the patients. This right has been progressively extended to include services from the private sector and now patients can freely choose either a private specialist physician or any hospital (outpatient or inpatient, public or private) through a GP referral (Figure 4). The only limitation is that the hospital has a contract with the Regional Health Enterprise (below). Patients also have the right to receive specialist medical assessments within thirty days after GP referral, and to receive an individual estimated time limit within which diagnosis and, eventually, treatments have to take place. If the time limit is exceeded, then the NIS is given the responsibility to provide treatment either through the private sector or abroad with costs financed by the regional health enterprise (see below). This could increase expenditure for hospitals by as much as $30 \%$ for each patient with unfulfilled treatment. On the other hand, by complying hospitals can get a higher transfer through the activity-based component.

18. The Health Enterprise Act, a major reform of ownership and organisation of specialised health care services, was implemented in January 2002 (so-called "hospital reform", see Ministry of Health and Social Affairs, undated). Hospital ownership was transferred from the Norwegian counties to the central government, in order to centralise political responsibility over the hospital sector in only one institution, i.e., the Ministry of Health and Care Services ${ }^{13}$, and to counteract the tendency of counties to want to have all types of hospitals. The latter resulted in wasteful duplication, increasing micro management of the hospitals to the detriment of quality and cost containment. Finally, shared responsibility between counties and the state over hospital care had often resulted in reduced accountability.

19. The hospital reform has established five geographically-based "Regional Health Enterprises" (RHE) each reporting to the Ministry of Health and responsible for delivering health services in their regions. The RHEs own the 33 local "health trusts" and are responsible for monitoring their costs and quality of services. ${ }^{14,15}$ The central government still defines their main health policy objectives as well as their financial means. The eastern health enterprise along with its trusts is the largest one covering $40 \%$ of the Norwegian population.

12. In the 2005 Budget, the DRG rate was raised from $40 \%$ to $60 \%$ in order to get agreement on other aspects of the budget.

13 Hereafter referred to as "Ministry of Health".

14. In the Norwegian documentation, health trusts are often called local health enterprises.

15. For example, Helse Vest (the western Regional Health Authority) is responsible for 4 health trusts mainly comprising hospitals and for one health trust comprising hospital pharmacies. This authority owns $95 \%$ of the hospital capacity, the rest being owned by the private sector (both for-profit and not-for-profit). 
Figure 4. Patient flows in primary and secondary care

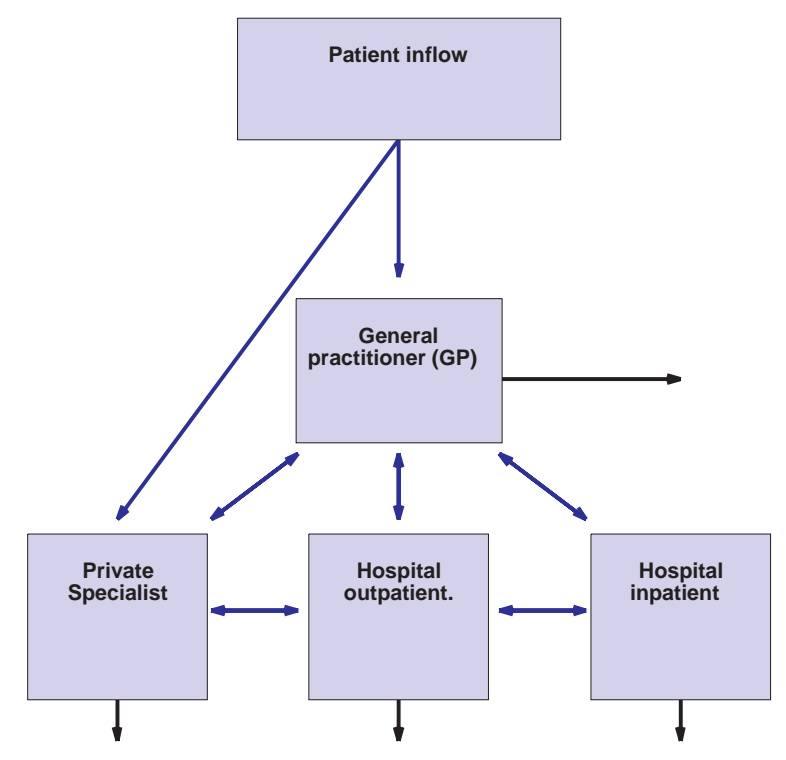

Source: Iversen and Kopperud (2003).

20. The executive board members of RHEs are appointed by the Minister of Health. Each board appoints its own chief executive officer (CEO) as well as the members of executive boards of each health trust in its region. Finally, the health trusts are managed by a CEO appointed by the trust board. The health trust CEOs also report informally to the CEO of the RHE. ${ }^{16}$ Thus, RHEs can exert significant influence on the management of the health trusts. As all trust guidelines derive from the RHE, mainly via the CEO of the enterprise, the management role of the trust boards is not clear. They are responsible for their budget, and in case of deficits, they can use short term financing and carry the deficits forward in the following year. Therefore, the state is not obliged to balance the budget ex post. However, hospital trusts are not allowed to go bankrupt.

21. When the reform was introduced, RHEs could choose a "competition model" where a large number of local hospitals would compete for clients or, at the other extreme, a "cooperation model" where local hospitals would be centralised in few big ones. Organisational choices have mainly favoured a system close to the "cooperation model". Accordingly, most health trusts currently centralise administrative functions of many hospitals, each of them specialising in specific treatments, though there is some scope for competition. Indeed, RHEs devote $2-3 \%$ of their budget to tendering services to private clinics. Furthermore, health trusts can in principle compete with each other for clients. Finally, for specialised ambulatory care patients can also choose self-employed physicians rather than hospital outpatient care.

\section{The positive effects of the reforms}

22. In principle, the combination of patient choice and DRG financing should introduce more incentives for hospitals to offer more, better and timelier services to attract clients. Moreover, the

16. The medical profession often holds top management positions in health trusts but this is not predominant in all health regions. The share of physicians at top management positions in health trusts range from around $15 \%$ in the western health region to $50 \%$ in the eastern one. 
transformation of public hospitals from administrative units into enterprises should have hardened their budget constraint. This should have helped to contain costs as well as levelling the playing field between the public and private sector. Measures of activity in general hospitals indicate that the reforms have had a positive effect (Table 2). Geographical variability also increased, especially concerning day treatments after 1999. Kjerstad (2003) shows that the new financing system has had a significant effect on both the number of patients treated as well as on the DRG points produced. ${ }^{17}$

Table 2. Activity of general hospitals

\begin{tabular}{|c|c|c|c|c|c|c|}
\hline & 1998 & 1999 & 2000 & 2001 & 2002 & 2003 \\
\hline Discharges per 1000 inhab. & 155.9 & 158.1 & 155.5 & 160.5 & 162.4 & 168.9 \\
\hline Day treatments per 1000 inhab. & 21.8 & 35.9 & 38.1 & 72.3 & 78.7 & 90.8 \\
\hline Outpatient consults per 1000 inhab. & 754.2 & 773.3 & 802.9 & 798.2 & 689.7 & 724.9 \\
\hline $24 \mathrm{~h}$ beds per 1000 inhab. & 3.3 & 3.2 & 3.2 & 3.1 & 3.2 & 3.2 \\
\hline $\begin{array}{l}\text { ALOS }^{1} \\
\text { Coefficient of variation across regions }\end{array}$ & 6.3 & 6.2 & 6.1 & 5.9 & 5.8 & 5.6 \\
\hline Discharges per 1000 inhab. & 0.14 & 0.15 & 0.14 & 0.15 & 0.16 & 0.16 \\
\hline Day treatments per 1000 inhab. & 0.45 & 0.08 & 0.12 & 0.23 & 0.24 & 0.28 \\
\hline Out patient consult per 1000 inhab. & 0.10 & 0.10 & 0.11 & 0.12 & 0.13 & 0.13 \\
\hline $24 \mathrm{~h}$ beds per 1000 inhab. & 0.17 & 0.17 & 0.18 & 0.17 & 0.17 & 0.18 \\
\hline $\mathrm{ALOS}^{1}$ & 0.05 & 0.06 & 0.05 & 0.05 & 0.05 & 0.06 \\
\hline
\end{tabular}

1. Average length of stays. It excludes day treatments.

Source: Ministry of Health.

23. Improvements in terms of input rationalisation are harder to detect. Since 1998, the number of beds per inhabitant has remained broadly stable whereas the average length of stays -- excluding day treatments - has decreased considerably in all regions. Otherwise, inputs have surged since the introduction of the DRG mechanism after a period of relative stability during the 1990s when hospital services were financed only through block grants (Figure 5). ${ }^{18}$ Expenditures on inputs accelerated after the introduction of the hospital reform. Statistics Norway estimates that in 2002 hospital expenditures increased by $22 \%$ in nominal terms and by $13 \%$ in real terms compared with the previous year, from already high growth rates of 12 and 9\%, respectively, in 2001. A major reason for this cost surge was the very large pay increases granted to hospital doctors in 2002-2003. Subsequent wage increases have been much more modest.

17. For his estimations, Kjerstad (2003) exploits the fact that when the reform was introduced some counties financed hospitals with the partial activity-based system whereas others continued financing them only with block grants. However, all counties received activity-based financing from the state.

18. Before the 1980s, hospital financing was based on the number of beds and this explains the significant rise of inputs during the 1970s in Figure 5. 
Figure 5. Costs in somatic and psychiatric specialist services 1970-2003 ${ }^{1}$ In thousand NOK at 2003 prices

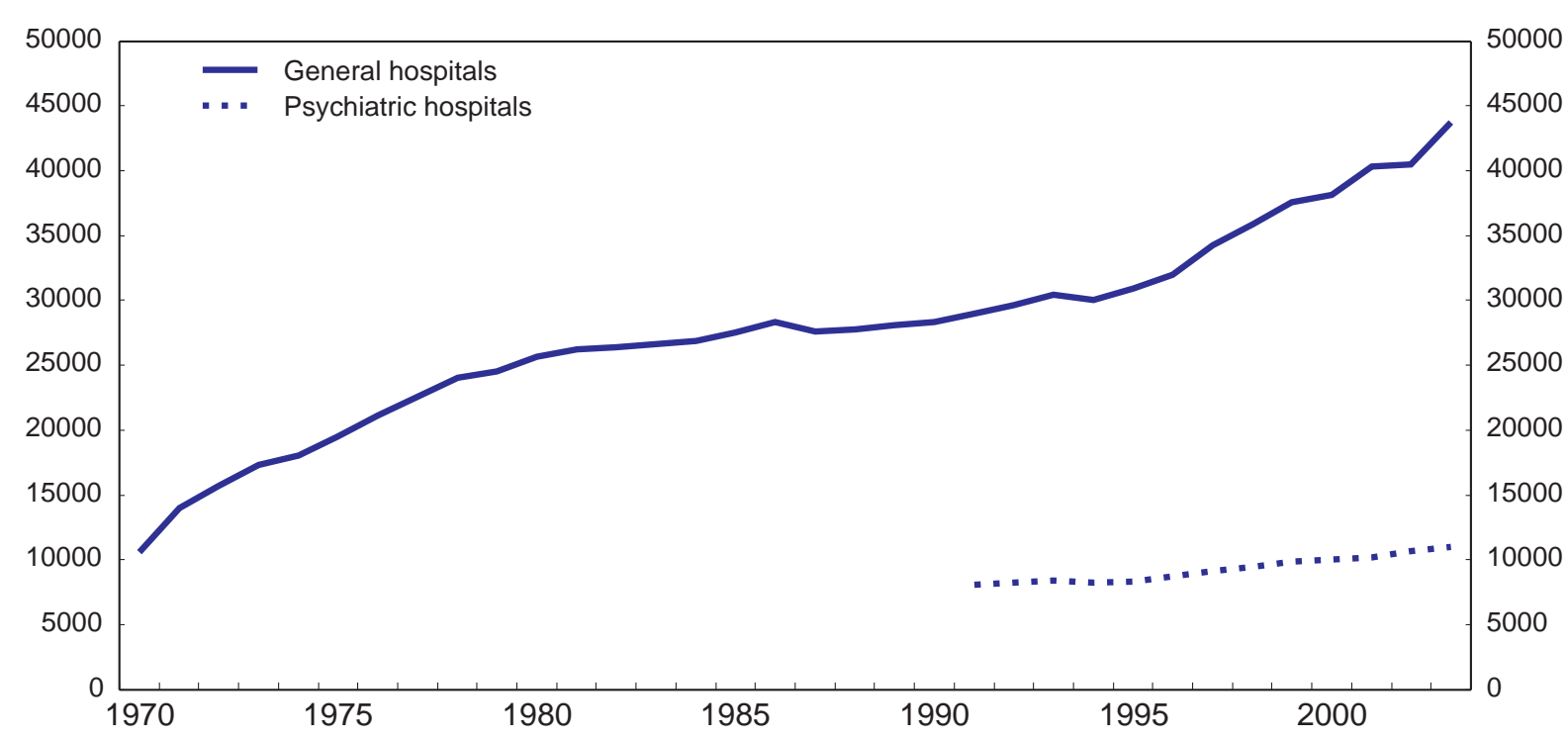

1. Excluding capital costs.

Source: SINTEF Health Research.

24. An analysis based on a comprehensive definition of output and inputs by Biorn et al. (2003) estimates that reforms led to an improvement of hospital "technical efficiency". ${ }^{19}$ A recent update carried out by the SINTEF research centre shows that the bulk of the improvement took place in 1997 when the DRG mechanism was introduced (Figure 6), and has started to rise again only after the implementation of the 2001 hospital reform. ${ }^{20}$ Moreover, the average waiting time has been reduced since $2000 .{ }^{21}$ After the hospital reform, the path of reduction was even more marked and waiting times in mid-2004 were around $40 \%$ lower than at the beginning of 2002 .

19. Technical efficiency is defined as output per unit of inputs whereas cost efficiency is defined as output per unit of NOK. For a discussion of cost efficiency see the section on human resources below.

20. Nevertheless, the calculations in Figure 6 are based on the development of reported DRG points, and presuppose that these numbers reflect actual activity. The existence of DRG "creep", that is changes in the way treatment is reported (e.g. more complete registrations) is not taken into account in this figure, leading to an overestimation of the development of efficiency in the period.

21. Waiting times have especially decreased for patients with unfulfilled waiting-time guarantees, i.e. whose waiting times are higher than the maximum time initially guaranteed by the hospital. 
Figure 6. Hospital efficiency 1992-2003

$$
1992=100
$$

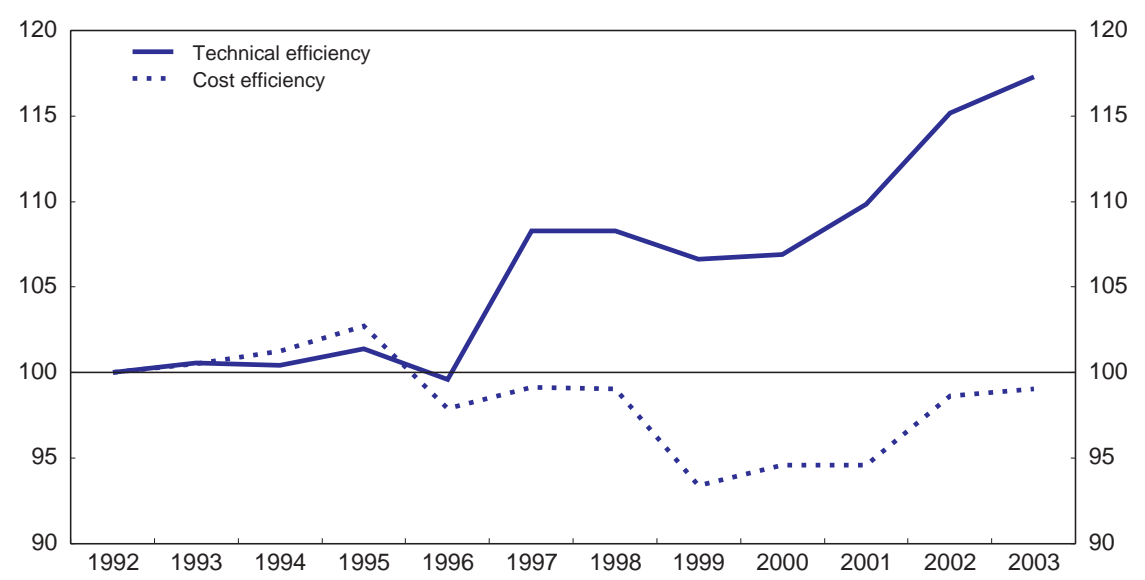

Source: SINTEF Health Research.

But outstanding issues remain on costs and deficits,...

25. Since their establishment in 2002, all RHEs except the eastern one have constantly run deficits, reaching around NOK 2 billion in 2003 and 2004 (around EUR 250 million), reflecting higher production than originally expected (Table 3 ). Hospital sector deficits are not included in the Norwegian measure of public sector deficits. If health enterprises treat more patients than budgeted for initially, then in principle the state should reimburse only $60 \%$ of the average costs through the activity-based component while the block-grant component should be left unchanged. As $60 \%$ of average costs is probably lower than total marginal costs, treating more patients than budgeted for should not be remunerative for health enterprises.

Table 3. Activity growth in general hospitals (percentage points)

\begin{tabular}{lcc}
\hline Year & Growth in DRG points & ${\text { Targets for } \text { growth }^{\mathbf{1}}}$ \\
$1992-1996$ & $2.0^{2}$ &.. \\
$1997-2000$ & $3.2^{2}$ &.. \\
$2000-2001$ & 4.5 & 2.0 \\
$2001-2002$ & 2.6 & 1.5 \\
$2002-2003$ & $7.0^{3}$ & 0.0 \\
$2003-2004$ & $1.5^{3}$ & 0.0 \\
\hline
\end{tabular}

1. National budget.

2. Average yearly increase.

3. Estimates.

Source: Hagen (2004).

26. The expectation of ex post financing by the central government is probably the reason behind this increased activity. In principle, the block-grant component should be determined on the basis of objective criteria related to demographics. In reality, the parliament has often topped up initial grant allocations with general additional allocations. ${ }^{22}$ Other budgetary funds based on discretion rather than on objective criteria

22. In 2002, additional grants because of higher activity amounted to NOK 730 million, in 2003 to NOK 2.2 billion and in 2004 to NOK 0.5 billion. In 2002, an additional NOK 1.0 billion was granted to finance higher wage expenditures and emerging deficits, and NOK 500 million in 2004 to finance emerging deficits. 
are also being granted to hospitals in more remote areas where lack of scale economies could increase costs, to hospitals with highly specialised functions, e.g., dealing with rare diseases, and to hospitals treating patients from other regions ("patient flows"). The government is currently attempting to find objective criteria for funding related to highly specialised services or to patient flows.

27. In 2003 the parliament decided that health enterprises should reach balance by 2005 and maintain it afterwards. ${ }^{23}$ In 2004, the parliament decided that the Southern RHE need reach balance only after 2005. In 2005, the parliament decided that all the RHEs should reach balance by 2006 . This more favourable treatment for enterprises with the highest deficits could be a disincentive to implementing more ambitious cost-cutting or efficiency measures.

28. Before the hospital reform, the owners of the hospitals (the counties) used an annual average of NOK 3 billion each year in the 1990s on investments. Subsequently, investments are still financed through block grants from the central government but with no earmarking, and health enterprises have been required to include capital depreciation in their budget. ${ }^{24}$ Nevertheless, a sharp increase in hospital investments has occurred since 2002, with their level $80 \%$ higher than the average of the 1990s in $2004 .^{25}$ This is likely to put pressure on RHE budgets in the next few years because of increasing debt payments as well as capital depreciation.

29. This investment surge was unexpected especially because higher efficiency had generated overcapacity in many health trusts. RHEs had accordingly started to close down some small local hospitals or departments while others have been merged. However, restructuring has met with local opposition and, in some cases, the Ministry of Health has intervened. Restructuring has been less than optimal and overcapacity remains an issue exacerbated by the hospital investment boom. Some public hospitals have started to look for clients through advertising.

\section{... undesired shifts of activity and financial resources...}

30. Despite the existence of a disease-priority system, ${ }^{26}$ in many instances activity has been directed rather towards more remunerative disease groups ("cherry picking"). However, these activities do not necessarily represent priorities from a social point of view. A clear example of the negative effects of "cherry picking" has been the doubling of surgery for reducing snoring from 1999 to 2003 because of profitable reimbursements (Christensen et al., 2004). As a result, the Ministry of Health reduced the reimbursement for snoring surgery by two thirds in 2004. Another problem is that the DRG compensation

23. For example, Bergen Hospital -- the largest in the western health region -- has cut human resources and has introduced budget responsibility at decentralised level. This has led to wage moderation as well as to a reduction of investments in new technology. This reduction could be beneficial for the hospital as equipment is not used at full capacity. In contrast, building overcapacity does not seem to be a problem for Bergen Hospital.

24. Health enterprises can borrow from the state to finance their investments. In $2004,40 \%$ of investments were financed through loans from the state. A few large hospitals have been given special grants from the state.

25. The increase in real terms is calculated by the OECD assuming that the increase of the hospital investment deflator in 2004 compared to the average in the 1990s is the same as for the deflator of total public investment.

26. The Act on Specialised Health Care identifies the main criteria for prioritisation of specialised treatments: a) that the patient will suffer a certain loss of length or quality of life if treatment is not given; b) that the treatment is thought to bring benefits to the patients; c) that the costs to provide the treatment are reasonable in relation to the benefits. 
system could take two years before adjusting to new technologies so that the cost of treatments could be over or under-estimated by the system thus leading to over or under-supply of treatments. ${ }^{27}$

31. Another drawback of the current financing system is that out-of-pocket payments are absent for same-day treatments but they are required for outpatient care. At the same time, same-day treatments are remunerated by the government more generously than outpatient care. Therefore, in order to attract patients as well as to increase revenues hospitals might have shifted some activity from outpatient care to same-day treatments, which is not cost-effective (Table 2).

32. An example of misusing the system ("DRG-creep") has emerged, like unnecessarily adding secondary diagnoses or claiming for treatment more than once. This underscores the inadequacy of hospitals' internal control systems and the need to improve governance of the current institutional structure. More control of this phenomenon has now been introduced by the Ministry of Health under the advice of a national board mainly composed of doctors.

33. Finally, there is mounting concern that putting too much emphasis on activity-based financing takes away resources from activities that are less profitable for hospitals but could be socially desirable, like the treatment of rare diseases, or that are left outside the activity-based mechanism, like mental health. Activity levels in psychiatric hospitals have been lower than in general hospitals, contrary to national priorities. The Norwegian authorities are also considering introducing the DRG system in psychiatric health care, at least for priority patients.

\section{.... and competition in the hospital sector}

34. The hospital reform has raised some concerns regarding competition. ${ }^{28}$ The re-organisation of hospital trusts under five RHEs has led to high concentration in the sector, and each health trust is effectively a local quasi-monopolist, especially for some specific treatments (Brekke, 2002). Indeed, despite a recent increase of private provision of health services, ${ }^{29}$ the scale of for-profit private hospitals with a currently less than $5 \%$ market share is small. Private clinics usually have to specialise in order to become more efficient and profitable, and their activity is often limited to same-day treatments. Furthermore, regional health enterprises are both purchasers of health services, as they have to ensure that demand for health care services is fulfilled by adequate supply, from either public or private hospitals, but they are also providers of health care services. This dual role could be an obstacle to a level playing field between public and private institutions. According to the Antitrust Authority, the common practice is to prioritise the request for services from the public sector with the private sector relegated to a residual role. ${ }^{30,31,32}$ Overcapacity in public hospitals could exacerbate this problem.

27. Other adverse incentives could be present in a DRG system. Remunerations of DRG points are defined by taking costs in a sample of hospitals as a benchmark. If hospitals are successful in reducing their unit costs, net revenues increase as remuneration remains unchanged. However, this could also introduce disincentives for efficient hospitals to cooperate with inefficient ones. In addition, there could be some free riding on decisions regarding machinery investments as these purchases can affect the remuneration of DRG points for the whole system but costs rise only in the hospitals that have actually undertaken them.

28. As most of specialised health care is reimbursed by the state, competition among hospitals should be based on quality and availability of services rather than price.

29. After the hospital reform, the Ministry of Health has granted permission to 8 new private hospitals to operate. These signed a contract with one or more regional health authorities. However, with an average of only 5 beds per hospital their capacity is small.

30. In laboratory services, there have even been some steps backward after the hospital reform. Indeed, private laboratory services were previously reimbursed with activity-based financing but from September 2005 half of the transfers will be given to the regional health authorities that can use them at their discretion, i.e. they can choose the providers without tender. 
35. Finally, few patients move from their region or area of residence to be treated, perhaps because the "money-follows-the-patient" principle has not been fully applied. Reimbursement is not automatic but depends on the agreement between the two health regions. Therefore, a health region does not necessarily have incentives to attract patients from outside its own region, while less efficient RHEs could have an incentive to refuse an agreement with more efficient ones in attempt to protect its own hospitals from more competition. ${ }^{33}$ To improve cross-regional competition, the government has required enterprises to pay $80 \%$ of the DRG price for patients deciding to be treated in hospitals outside their region of residence.

\section{Self-employed specialised physicians}

36. Self-employed specialists account for around $17 \%$ of the total specialists. They can establish throughout the country, sign agreements with regional health authorities for the delivery of services to patients, and they are financed in a similar way to that for hospital outpatient care. Their geographical distribution is far from uniform, because they might not find it profitable to establish in remote areas. At the same time, regional authorities in such areas could have a preference to rely on hospital outpatient care to provide specialised services. The unequal distribution makes the authorities' equality objectives in the use of specialised care more difficult to reach. Indeed, Iversen and Kopperud (2003) and (2005) find that, controlling for patient characteristics, capacity and greater distance from specialist physician ambulatories reduces the probability of patients' visit, whereas this is not an issue for hospital outpatient care.

\section{Primary care}

37. Municipalities are responsible for the provision of primary care, which is mostly performed by self-employed GPs signing a contract with the municipalities (90\% of the total). The rest is accomplished by GPs working as municipal employees on a fixed salary.

\section{The new "patient-list" system}

38. In June 2001, the government introduced major changes in primary care through the so-called "patient-list" system. The objective of the reform is to improve GP access for patients and to strengthen the relationship between patients and doctors. Patients are asked (but not obliged) to state their preferences for registering in the list of their "regular" GP, who becomes a "gatekeeper" for further medical services, with the responsibility to co-ordinate these services. Patients on a GP list should be able to get an appointment with their GPs in a reasonable period of time as well as to be able to contact the GP by telephone for advice and enquiries. They have the right to request a second opinion from another GP. Broadly $70 \%$ of GP earnings continues to be financed through a fee-for-service mechanism reimbursed by the National Insurance System (NIS) and a consultation fee paid out-of-pocket by patients. The remaining $30 \%$ is based on the number of patients on the GP's lists and financed by municipalities via block grants from the state. This capitation component has substituted the previous input-based allowance and is meant to prevent

31. The Antitrust Authority has started analysing whether hospitals also should comply with the provisions of the Competition Act. Even if this is found infeasible under current legislation, the Authority will still retain its advocacy role in this sector.

32. Another feature preventing a level playing field is that the central government level of the public sector does not pay VAT on outsourced services contrary to what happens for the private sector (local governments were made subject to a VAT requirement as of 2004). The former government had planned to remove this difference starting from 2006; for example, hospitals would have to pay VAT on outsourced cleaning. However, the new government (elected in October 2005) scrapped this provision in its rewrite of the 2006 Budget.

33. Generally speaking, however, the Ministry of Health considers the level of co-operation among regional health authorities more satisfactory than that among counties before the reform. 
"cream-skimming" behaviour. Small municipalities (less than 5000 residents) can top up self-employed GP earnings with additional income to compensate for short patient lists. ${ }^{34}$

\section{The benefits of the reforms}

39. As a result of the patient-list reform, $98 \%$ of the population is now registered with a GP. According to surveys by the Ministry of Health (2004), patients and GPs seem to share a broad appreciation of the reform: patients find that accessibility has improved, while GPs consider it more important now to keep patients satisfied and provide them with better services (Carlsen and Norheim, 2003). Because of greater commitment by GPs, patients have established longer-term relationships with them.

\section{Some outstanding concerns}

40. All the above benefits have to be balanced against the higher costs induced by the reforms, with payments to GPs paid by the municipalities having exceeded initial allocations from the central government. The government feels that the activity-based component might have increased because of greater efforts by GPs to satisfy patients.

41. Concerns are also rising on the increasing financial burden for small municipalities. Half of the GPs in municipalities with fewer than 2000 residents are paid on a fixed wage basis. As for the self-employed GPs, both the capitation and the activity-based components might not be as attractive as in more populated areas. This does not necessarily translate into lower quality but it does translate into higher costs for small municipalities in order to attract GPs (Table 4). Moreover, patients in municipalities with a high turnover of GPs are less satisfied with the access to the services. ${ }^{35}$

Table 4. Municipal expenditure for primary care per inhabitant by size of municipalities Share of total expenditure

\begin{tabular}{lcc}
\hline & 1999 & 2002 \\
\cline { 2 - 3 } Less than 1999 inhabitants & 66.0 & 83.0 \\
2000-4999 inhabitants & 64.0 & 72.0 \\
5000-9999 inhabitants & 58.0 & 61.0 \\
10000-19999 inhabitants & 57.0 & 56.0 \\
20000-29999 inhabitants & 55.0 & 51.0 \\
30000-49999 inhabitants & 55.0 & 51.0 \\
More than 50000 inhabitants & 49.0 & 50.0 \\
All & 58.0 & 56.0 \\
Coefficient of variation & 0.10 & 0.21 \\
\hline
\end{tabular}

Source: Statistics Norway, Primary physician service, municipal expenses, 2002.

42. The objective of strengthening the role of the GP as "gatekeeper" is not being fulfilled as expected, and after the reform this role might actually have declined. Iversen and Kopperud (2005) estimate that patients having a personal GP show a higher probability of at least one visit to a specialised physician or to hospital outpatient care per year. Indeed, the number of referrals and of drug prescriptions

34. According to the Ministry of Health, some municipalities have also had to pay fixed-wage GPs more than stated in regular tariffs in order to retain them.

35. See Lian (2003). 
has increased after the introduction of reform. ${ }^{36}$ No convincing explanation of this unexpected finding is available.

43. Finally, increasing GP commitment towards patients might also have had an adverse impact on the involvement of GPs in public general medical duties, whereas co-ordination between primary and secondary care needs to be improved. In autumn 2003 the government therefore established a commission to analyse and propose measures to enhance co-operation among primary and secondary care and their recommendations were published in spring 2005 (see NOU 2005:3).

\section{Mixed evidence on "supplier-induced demand"}

44. GPs often experience patient shortage, i.e., the number of patients in their lists is lower than the stated preferred one. Indeed, despite improvements, two years after the patient-list reform almost a quarter of GPs -- all of them in urban areas -- still experienced patient shortage. This could be a problem if GPs with short lists provide more services than socially desirable either to compensate lower earnings from the capitation component or to attract and retain new patients in a context of asymmetric information. ${ }^{37}$ Empirical evidence indeed shows that Norwegian GPs with patient shortages have higher service intensity and, hence, income per listed person than the other GPs. The evidence suggests that referrals to neighbouring hospitals are also higher following the reform. Available evidence does not reveal whether these additional services are optimal from the patients' (or society's) point of view so that the presence of "physician-induced demand" is uncertain. ${ }^{38}$

\section{Long-term care}

45. Municipalities are also responsible for ensuring long-term care to the elderly through either public or private institutions. The central government establishes minimum standards to be provided by municipalities, which finance it mainly through discretionary allocations of block grants received from the central government and partially via fees from patients living in public facilities or receiving home care. ${ }^{39}$

46. Because of lack of resources, municipalities are frequently unable to provide enough assistance to the elderly so that hospitals have to provide assistance for dependent persons not having an acute medical need. Such hospital assistance is much more costly than nursing home or community-based care. As a response, a national objective has been set to reach enough nursing home capacity so as to accommodate at least $25 \%$ of people aged 80 years and older. A number of municipalities are currently carrying out a major

36. According to Grytten and Sorensen (2003), there is a very weak tendency of increasing number of referrals. A survey among GPs in 1998 and 2002 showed an increase in the actual number of referrals of 11 per year among the GPs who were earlier on a fixed salary and of 15 per year among those who were selfemployed before the reform. Iversen and Kopperud (2005) show a weak decrease in the referral rate for patients having been listed with a GP for a longer period of time, indicating that continuing in doctorpatient relationships led to changes in referral practices.

37. It could also be the case that GPs with no patient shortage are actually rationing services as they have reached the desirable number of clients. In this case, the amount of services provided by GPs with patient shortage could actually represent the desirable one from the patient's point of view. In this case, the issue is whether the public sector should pay for these additional services or should these be paid through private sources of financing.

38. See Iversen, 2004 and 2005, and Grytten and Sorensen (2004).

39. Such fees are low, for example, patients can be asked to pay only the equivalent of 4 hours a month for the time auxiliary nurses spend in their home providing home care. The actual time spent is usually higher. Medical assistance at home is free of charge, while there is some cost sharing of help with practical tasks at home. How much is paid varies across municipalities and is often means-tested. 
restructuring of nursing homes in order to attain national standards and to contain costs (see Box 1 for an example of restructuring in the Bergen municipality).

\section{Box 1. Long-term care in the Bergen municipality}

Bergen municipality total revenues amounted to around NOK 10 billion (around EUR 1.2 billion) in 2004. Almost $30 \%$ of revenues are allocated for services to the elderly and handicapped. Purchase of elderly care by the municipality is carried out through competitive tendering open to private institutions. Contracts generally last two years and specify ex ante quality objectives, which are monitored ex post by the municipality.

In 2002 , the number of people aged $67-79$ were $8.8 \%$ of the total population; aged $80-90$ were $3.9 \%$ and aged more than 90 were $0.6 \%$. In 2020 , the respective shares are expected to be $10.6,3.7$ and $0.9 \%$. A restructuring of the facilities for the elderly is currently taking place to tackle the expected increase in long-term care demand because of population ageing. After restructuring, the Bergen municipality will be responsible for around 110 "units", mainly nursing homes. Each unit is being made responsible for its own budget with the objective of better controlling costs and increasing transparency.

The restructuring of buildings is carried out with the objective of tripling the share of short-term facilities over the total, now reaching around $10 \%$. This is mainly attained by renovation of existing buildings aiming at a more efficient division of space. New facilities are also being built. A greater stress on short-term facilities rather than long-term ones should allow more people to be treated or taken care of in their homes. This could both increase the likelihood for the elderly to recover after a surgery or an accident and reduce costs for the municipality. In fact, the municipality estimates that unchecked admittance to long-term institutions both increases costs and reduces recovery rates. Furthermore, community-based care could allow a decrease of elderly stays in the Bergen hospital thus freeing capacity for other activities. Nevertheless, the shift to community-based care sometimes finds resistance among traditional nursing home employees, citizens at large and local politicians.

Despite ad hoc transfers from the central government to build new nursing homes, the restructuring has contributed to increasing deficits for the municipality especially starting from 2002 . The cumulated debt has reached a significant NOK 85 billion, i.e., almost 9 times the municipality annual revenues, and the objective is now to reduce it also through personnel cuts.

\section{Human resources in the health sector}

47. The Ministry of Health controls the number of posts in the medical profession nationwide. Problems in recruiting or retaining health care staff emerged at the end of the 1990s, especially for nurses and GPs. The shortage problem was concentrated in remote areas even though the number of health professionals per inhabitant in these regions was already higher than average (Table 5).

48. The main reasons for the shortage were an insufficient number of training programmes linked to the health profession, and working conditions that were considered unsatisfactory either because of relatively low wages or a high share of unconventional work (i.e., shift work) not adequately remunerated. This has led to a significant number of staff -- especially nurses -- either to leave or to work part-time. ${ }^{40}$

40. Askildsen, Baltagi and Holmas (2003) show that working conditions and shift work are important determinants of labour supply by nurses. They also show that substitution effects seem to slightly dominate income effects so that an increase in wages has a positive but small impact on labour supply. Holmas (2002) also shows that better working conditions --especially reduced shift work -- and higher wages have a negative impact on nurses' decisions to quit the health profession. Baltagi, Bratberg and Holmas (2003) show that hospital physicians are quite responsive to wage changes. 
Table 5. Number of health professionals ${ }^{1}$

\begin{tabular}{lrr}
\hline & 1999 & 2003 \\
\cline { 2 - 3 } Physicians per 10 000 inhabitants & 7.9 & 8.5 \\
Remote municipalities & 10.2 & 11.3 \\
Fairly remote municipalities & 8.0 & 9.2 \\
Fairly central municipalities & 7.6 & 8.1 \\
Central municipalities & 7.4 & 7.8 \\
Physiotherapists per 10 000 inhabitants & 7.6 & 8.3 \\
Remote municipalities & 7.1 & 8 \\
Fairly remote municipalities & 7.1 & 7.9 \\
Fairly central municipalities & 7.6 & 8.3 \\
Central municipalities & 7.9 & 8.4 \\
Midwives per 10 000 born & 45.3 & 50.6 \\
Remote municipalities & 122.2 & 127.4 \\
Fairly remote municipalities & 65.7 & 79.1 \\
Fairly central municipalities & 32.3 & 38.4 \\
Central municipalities & 30.1 & 36.2 \\
Public health nurses per 10 000 children 0-4 years & 54.6 & 64.1 \\
Remote municipalities & 63.4 & 84.0 \\
Fairly remote municipalities & 58.7 & 69.9 \\
Fairly central municipalities & 56.1 & 65.5 \\
Central municipalities & 51.2 & 58.4 \\
\hline
\end{tabular}

1. Excludes personnel working in institutions for the aged and home-based services.

Source: Statistics Norway, Municipal health and care services, final figures, 2003.

49. The problem now seems less serious mainly thanks to the Ministry of Health strategy to open positions mostly where shortage problems are most pressing. Other measures to reduce shortages have included ad hoc training, higher compensation for medical trainees and increased wages. In particular, in the period 2002-2003 hospital doctors benefited from a substantial 16 $\frac{1}{2}$ per cent wage increase, around 6 percentage points higher than the average wage increase in Norway. Hospital doctor wages remained broadly stable in 2004 . The wage surge for hospital physicians as well as for other personnel contributes to explaining the rise in unit labour costs (declining "cost efficiency") despite a rise of production per personnel (rising "technical efficiency") induced by reforms (Biorn et al., 2003, and Figure 6). These wage rises have also been one of the reasons for persisting financial deficits at RHEs.

50. Thanks to wage rises, working conditions for the health profession in Norway have generally improved to the point where any serious shortage could in theory be solved by recruiting abroad. Indeed, in 2001, foreign-trained physicians were $12^{1 / 2}$ per cent of the total, and this could have been even higher but for the need to learn a new language. According to the authorities, some skill shortages indeed persist in some specific areas like mental and psychiatric health, especially for children, for which fluency in Norwegian is probably more important. Shortage is also a problem for dentists and long-term-care nurses, and in general in the most remote areas.

51. Finally, the variability of physician skills across the country is considered unacceptably high by the authorities, despite a very similar initial training for young doctors nationwide. This could be because doctors in more remote areas miss the opportunity of knowledge spillover and do not or cannot compensate for this through individual skill updating. The National Centre for Health Service Research, a government agency, is now in charge of spreading best practices nationwide (see below). 
52. For the medium-term (by 2020), the forecasting model at Statistics Norway foresees that thanks to the recently implemented measures, shortages of nurses (holding tertiary education degrees) and physicians is likely to be avoided despite population ageing (Stolen and Texmon, 2002). Nevertheless, supply shortages are predicted for dentists, auxiliary nurses (holding secondary education degrees), health visitors and occupational therapists.

\section{The pharmaceutical sector}

53. Pharmaceutical expenditure as a percentage of GDP is lower than in many other OECD countries, but in the past six years public expenses related to pharmaceuticals have increased by an average of approximately $8 \%$ per year. The variety and availability of products is not as broad as in other OECD countries and the time for launching a new product is quite long. ${ }^{41}$ The Norwegian Medicines Agency (NoMa) decides on the new drugs to be given market authorisation. If companies apply for reimbursement of the new drug, the application is assessed and decided upon by NoMa. Cost effectiveness considerations play an important role in this assessment. If reimbursement of a new pharmaceutical product is associated with a substantial cost increase, this has to be handled by the Ministry of Health and Parliament through prioritisation decisions in the yearly budget process. The resulting waiting period for putting new drugs on the list for reimbursement could reach up to 2-3 years. Nevertheless, the final decision is often made on the basis of effectiveness of the drug's benefits independently of its costs, reflecting pressures from both users and producers of pharmaceuticals.

54. The market for pharmaceuticals underwent a major change with the 2001 Pharmaceutical Act. This removed the requirement that pharmacy owners hold a tertiary degree without at first necessarily lifting location restrictions. This induced three retail chains -- integrated with the wholesale counterparts -to buy up most of the small pharmacies, thinking that there would still be monopoly rents deriving from location restrictions. However, the ceiling on the number of pharmacies was finally removed, their number being increased by around one third from 2001 to 2005, and they are now open longer hours. Nevertheless, the market is now highly concentrated and dominated by the three retail/wholesale chains, enjoying preferential relationships with producers which act as a barrier to entry. An initiative has been introduced more recently to increase drugs' availability, and reduce concentration of the market by permitting petrol stations and other retailers to sell a selection of non-prescription drugs, and around the clock.

55. The prices of patented drugs are heavily regulated. Their maximum price is linked to the average of the three lowest prices in a basket of nine EU-15 countries. This system is designed to constrain costs. There is a political wish to keep the co-payment for patients low. Patients will as a result not face budget constraints when using drugs, and the price mechanism will not work in the medicines market. Hence, price regulation is necessary. A more market friendly solution would reduce or eliminate altogether price regulations while increasing patient co-payments for the non-poor. This kind of policy change would likely increase prices for patented drugs, but lower prices for generic drugs.

56. No longer patented brand drugs in principle compete with patented drugs as well as generic versions. Nevertheless, the prices of both no-longer-patented drugs and generics are high in Norway compared with those in other northern European countries, themselves already high in international terms. This reflects, first, that the reimbursement for generics is based on the (high) price of the originally patented product. Second, weak competition in the wholesale and retail segments of the pharmaceutical chain prevents generics being sold more widely and at a lower price. Finally, the state reimburses prescription drugs almost to the full so that consumers do not search hard for lower prices, and may believe that branded drugs signal high quality. As a result, in terms of volume the share of generics drugs over total sales remains at $28 \%$.

41. See Table 8 in Farmindustria (2004). 
57. As a response, in March 2003 the government introduced an "index-pricing" system such that when selling no-longer-patented drugs prescribed by GPs, pharmacies could share with the government the savings from offering generics, and incidentally putting downward pressure on branded drug prices. In reality, this measure led to only limited public saving as well as to insignificant price effects. A new "step-price" model was introduced in the 2005 budget to increase the share of generics. With this model, the maximum reimbursement price for no-longer-patented drugs is fixed as a percentage of the price of the originally patented product on a sliding scale varying with time of patent expiration. ${ }^{42}$ If the patient refuses the proposed substitution, the difference between the actual and the step-price has to be paid by the patient and is not included in the ceiling of out-of-pocket payments. The pharmacies are obliged to offer at least one product in each pharmaceutical category at the "step-price". At the same time, pharmacists selling less expensive products than the "step price" can keep the difference as profits. This model is expected to produce saving of NOK 450 million (around EUR 55 million) for the state and NOK 70 million (around EUR 8.5 million) for households already in 2005.

\section{The role of government agencies}

\section{Norwegian Board of Health}

58. The Norwegian Board of Health has surveillance and control responsibilities on whether health care services are provided in accordance with existing legislation. It reports directly to the Ministry of Health but it is autonomous in its surveillance role. Its main task is to handle individual cases of deviations from rules or from professional norms, either initiating investigations autonomously or after complaints from patients. The latter seem to have increased significantly in recent years. Another important task is surveillance of the performance of the health care sector, working in cooperation with other institutions like the Ministry of Health and Statistics Norway to provide data and material to be used by the policymakers for their decisions. Finally, the Board performs audits on topics chosen on the basis of risk assessment. The criteria for choosing such topics are the number of people involved, even if the problem per se could be minor, or the size of the damage inflicted to patients, even if the number of patients involved is small. A share of the topics (around 10\%) is chosen by the Ministry of Health.

59. Activities of the local boards of health mainly involve working in the field. One general problem that they have identified across all counties is the scarcity of assessment, by both municipalities and health trusts, of the expected demand for services even though regulations require them to perform this regularly for their populations. Hence the supply of health services might not adequately match demand, and this might partly explain observed differences in the quality of service provision across the counties. Local boards have the role to encourage health institutions to perform risk assessments upon which they should build their activities so as to enhance both quality and efficiency. Moreover, health care institutions are increasingly asked to improve self-assessment capacity.

42. For drugs with sales above NOK 100 million (around EUR 12 million), the maximum reimbursement price (the "step price") is $70 \%$ of the price of the originally patented product in the first 6 months after the patent expiration, $50 \%$ after the sixth month and before one year, and 30\% afterwards. For drugs with sales below NOK 100 million, the maximum reimbursement price is $70 \%$ of the price of the originally patented product in the first 6 months after the patent expiration, $60 \%$ after the sixth month and before one year, and 50\% afterwards. 


\section{Norwegian Knowledge Centre for Health Services}

60. The Norwegian Knowledge Centre for Health Services is a new institution consolidating the activities of several former centres. ${ }^{43}$ It assesses the cost effectiveness of new treatments and technologies and monitors existing treatments and patients' satisfaction. The cost-effectiveness analysis of the Centre -- which also internalises ethical considerations -- should in principle be taken into account by the authorities when deciding on the reimbursement of treatments. But the link between cost effectiveness and the political decision to reimburse is not systematic. Indeed, this decision is more likely to be linked to the benefits of the treatments per se, independently from their costs.

\section{Agenda for future health care reforms}

61. Ensuring the continuation of high-quality health care to the whole population is a commendable objective to which the Norwegian authorities have devoted considerable efforts especially since the second half of the 1990s. If high quality and equitable access is valued highly by households, a rise in total health care expenditure faster than GDP is acceptable, even desirable. However, this choice should be based on adequate information of the benefits and costs of health services as well as on appropriate awareness of its sustainability over the medium-to-long-term. The appropriate split between public provision and out-of-pocket financing also needs to be taken into account, and could change over time. Hence although the growth of provision of health services may be socially optimal, the total level of spending on health — and within that public spending — may well be too high.

62. Reform experience in Norway shows that introducing incentives for more responsive service provision can be very successful in increasing and improving supply in the health care sector. Nevertheless, if these incentives are not appropriately designed, the resulting ex post costs could be constantly higher than what had been considered socially desirable ex ante. Pressure on the government is mounting to devote more public resources to health care. Insofar as medical costs rise because of lower than average productivity growth in the sector, then higher spending is to some extent eventually inevitable, even if reforms succeed in raising productivity levels in the shorter term. The question arises as to how much of any increase in costs arising from a rising volume of consumption of drugs and medical services should be publicly financed automatically. Arguably, as per capita income rises, the share of out-of-pocket payments could also rise, especially because Norway is a high-income country with a very low incidence of poverty, and especially for services which are ancillary, e.g., hotel-like services in hospitals. In some cases where out-of-pocket payments are absent, they could be introduced. At the same time, to continue ensuring an equitable access to health services, full or partial exemptions from payments should be devised for those who cannot afford necessary treatments, either because they have unusually low discretionary incomes, or chronic health problems, or because the available treatments are very expensive.

63. There have been some cases where budget deficits of health trusts have not been reflected in health trusts' accounts, but instead have been transferred to the RHE's accounts. This has led to confusion about the origins of deficits. Imposing more financial responsibility on health trusts could help to reduce deficits, as they are more insulated from political influence than are the RHEs. For example, the eastern health enterprise has imposed budget responsibility downstream to its health trusts, possibly explaining why health trusts there have increased activity only to a limited extent compared with health trusts in other

43. The Centre of Medical Methodology, the Foundation for Health Services Research and the Division of Health Services Research of the Health and Social Service Directorate at the Ministry of Health. 
regions. ${ }^{44}$ Health trusts should also be given more independence in the restructuring of their hospitals to tackle overcapacity. However, this might be more difficult now as a result of measures put into effect by the new government requiring the majority of the RHE's and health trusts' board members to be chosen from the regional and local political authorities. There have also been recent clear political signals that local hospitals are not to be closed down.

64. The financing mechanism should be modified to impose more financial discipline on hospitals. One option could be to reimburse only partially, and then up to a ceiling, spending over and above the levels previously identified by the parliament, as proposed by the Hagen commission (see Box 2). Downward adjustment of DRG rates should be introduced if volumes continue to rise faster than foreseen, as in Austria and Germany (OECD, 2003a). At the same time, RHEs or local health trusts should be made responsible for finding additional revenues should deficits arise, for example by introducing out-of-pocket payments by patients on top of those already enforced at the central level. In particularly egregious cases, the management of failing regional health trusts should be taken over for a limited time by the Ministry of Health.

\section{Box 2. The Hagen commission}

An ad hoc commission (the so-called Hagen Commission) $)^{1}$ was set up in February 2003 with the objective of delivering a report analysing financing issues in specialised health care. The Commission delivered the report in December 2003.

One of the main conclusions of the commission was that since the reimbursement system for specialised care had not changed after the hospital reform, the ownership structure per se could not be expected to change incentives for deficit control. The majority of the commission thus suggested changing the funding model along the following lines: a) the parliament decides on the total budget allocation for specialised health care; $b$ ) the total allocation is then distributed among RHEs according to a need-based capitation mechanism; c) RHEs and the central government agree on the level of activity that each RHE can achieve given assigned resources and also on the basis of cost estimates provided by an independent expert group; d) if, despite negotiations, activity is higher than agreed ex ante, then the central government would finance $50-60 \%$ of any excess activity of $2 \%$ while the rest would be entirely financed by RHEs. Moreover, RHEs would be given more freedom over their management activity and in particular over the choice of the financing method for health care providers.

The government and the parliament did not endorse this proposal for fear that it would be cumbersome to define regional activity levels and that RHEs would rely excessively on block grants for hospital care financing.

1. The commission owes its name to its chairman Prof. Terje P. Hagen.

Source : Hagen and Kaarboe (2004).

44. Another possible explanation is that the chief executive officer (CEO) of the eastern health enterprise had previous experience with the hospital sector at the county level before the reform. CEOs of the other RHEs had experiences in different sectors. If this is the main explanation, current deficits could just be a transitional phenomenon which should fade away as the new CEOs accumulate experience on the health care sector. 
65. The DRG system is based on resources and costs in some benchmark Norwegian hospitals and is therefore beneficial for strengthening yardstick competition, thereby enhancing incentives to run hospitals efficiently and with lower costs compared to the benchmark ones. However, if costs go down in all hospitals, the successive revisions of the system would result in continuously decreasing prices, which would hurt all hospitals. Collusion among them could thus arise and prevent costs from falling. ${ }^{45}$ This is more likely to happen now that the hospital sector is more concentrated. Therefore, benchmarks should be chosen also by looking at experience at the international level.

66. In primary care, the financing system has many benefits but has led to unexpected increases in costs. The patient-list system has not enhanced the gatekeeper role of GPs to adequate levels. To rectify this, an option could be to introduce a "practice profile" for GPs, based on best practice guidelines, themselves evidence-based. If the profile is very different from these, physicians should then be held accountable for their diverging practice. Moreover, the authorities could consider introducing financial responsibility for GPs on the use of private specialists, hospital care and prescription drugs by their patients, along the lines of what is being attempted in the United Kingdom (OECD, 2003a). This could also contribute towards improving co-ordination between primary and secondary care. In more populated areas there could also be scope for municipalities to group together for providing joint primary care services. This could free resources to be used in less populated areas where higher levels of GPs per capita and expenses are more difficult to avoid.

67. It is too early to assess whether the introduction of the step-price model for pharmaceuticals - a praiseworthy initiative in itself - will succeed in lowering the prices of no-longer-patented products. It does raise incentives for consumers to demand lower-price products rather than relying on pharmacies to supply them, which failed to bring savings in the past. However, the low ceiling on overall out-of-pocket payments by patients means that the incentive to ask for lower-price products disappears quickly. Moreover, no incentive has been introduced for GPs to prescribe lower-price products.

68. Reducing economic rents in the retail and wholesale pharmaceutical sector could also be an option for further savings. Nevertheless, fiercer competition from new entrants may have only limited effects: price competition is limited because reimbursement from the state is generous. Competition might thus be confined to quality, location and opening hours; and entry costs for new companies are high as they need to establish themselves also in the wholesale segment. It is hard in practice to get access to the direct relationships with producers enjoyed by incumbents, as the experience with resistance to selling drugs in non-conventional stores has shown.

69. Increasing the share of out-of-pocket payments could thus represent a means for achieving both higher saving and higher competition in the pharmaceutical sector. The increase could be attained through a rise in the ceiling of out-of-pocket payments. The authorities could also introduce more drastic measures to tackle the roots of the problem, namely the strong vertical integration and concentration in the wholesale and retail segments of the pharmaceutical market and the absence of incentives for physicians to prescribe generics rather than brand-name drugs.

70. Although in principle, new drugs and treatments are allowed only if cost benefit analysis indicates that this is worthwhile, in practice some expensive new drugs have been put on the list of reimbursable treatments at the request of Parliament, or members of Parliament, following pressure from voters. Such "fast-track" approvals should be followed by the standard, time-consuming, but objective analysis, to see if their continued presence is justified.

45. On the other hand, cooperation and coordination of RHEs and health trusts could sometimes help reduce costs, for example by centralising the purchase and use of equipment allowing equipment to be exploited more continuously. 


\section{Box 3. Summary of recommendations}

\section{Long term sustainability of health services}

Raise means-tested out-of-pocket payments for ancillary services: At the same time, to continue ensuring an equitable access to health services, introduce full or partial exemptions from payments for those who cannot afford necessary treatments, because they have unusually low discretionary incomes, or chronic health problems, or because the available treatments are very expensive.

Give health trusts more financial responsibility and independence: Because they are more insulated from political influence than are the RHEs, this could help reduce the deficits. Health trusts should also be given more independence in the restructuring of their hospitals to tackle overcapacity, notably by appointing professional managers to health trust boards.

Impose stronger cost control on hospitals in line with the Hagen commission proposals: Reimbursements should only be partial, and DRG rates should be adjusted downward if the supply of related services continues to rise faster than expected, while total costs remain within the budgetary envelope.

Benchmark the DRG system at an international level: to avoid continuously decreasing prices, which would hurt all hospitals and possibly lead to collusive behaviour between them.

Remove central government VAT preference for outsourced services, in line with the practice at the local government level: This would encourage a level playing field and thus stimulate competition in the health sector.

\section{Primary and secondary care}

Introduce a "practice profile" based on best practice guidelines and enhance responsibility for GP's: This should prevent divergent practice, introducing financial responsibility for GPs on the use of private specialists, hospital care and prescription drugs by their patients, and could also contribute towards improving co-ordination between primary and secondary care.

Consider raising the ceiling on overall out-of-pocket payments by patients and promote incentives to prescribe generics: the low ceiling on overall out-of-pocket payments by patients means that the incentive to ask for lower-price products disappears quickly. No incentive has been introduced for GPs to prescribe lower-price products.

\section{Drug prescriptions}

Carefully monitor the wholesale and retail pharmaceutical markets and intervene forcefully in cases of overt or tacit anti-competitive behaviour.

Implement cost-benefit analysis on expensive new drugs, reimbursed on "fast-track" approvals: This should contribute to a more objective analysis, to see if their continued presence is justified. 


\section{ANNEX A1}

\section{International health statistics: background information}

Figure A1.1. Expenditure and health status in OECD countries In 2002 or nearest year available
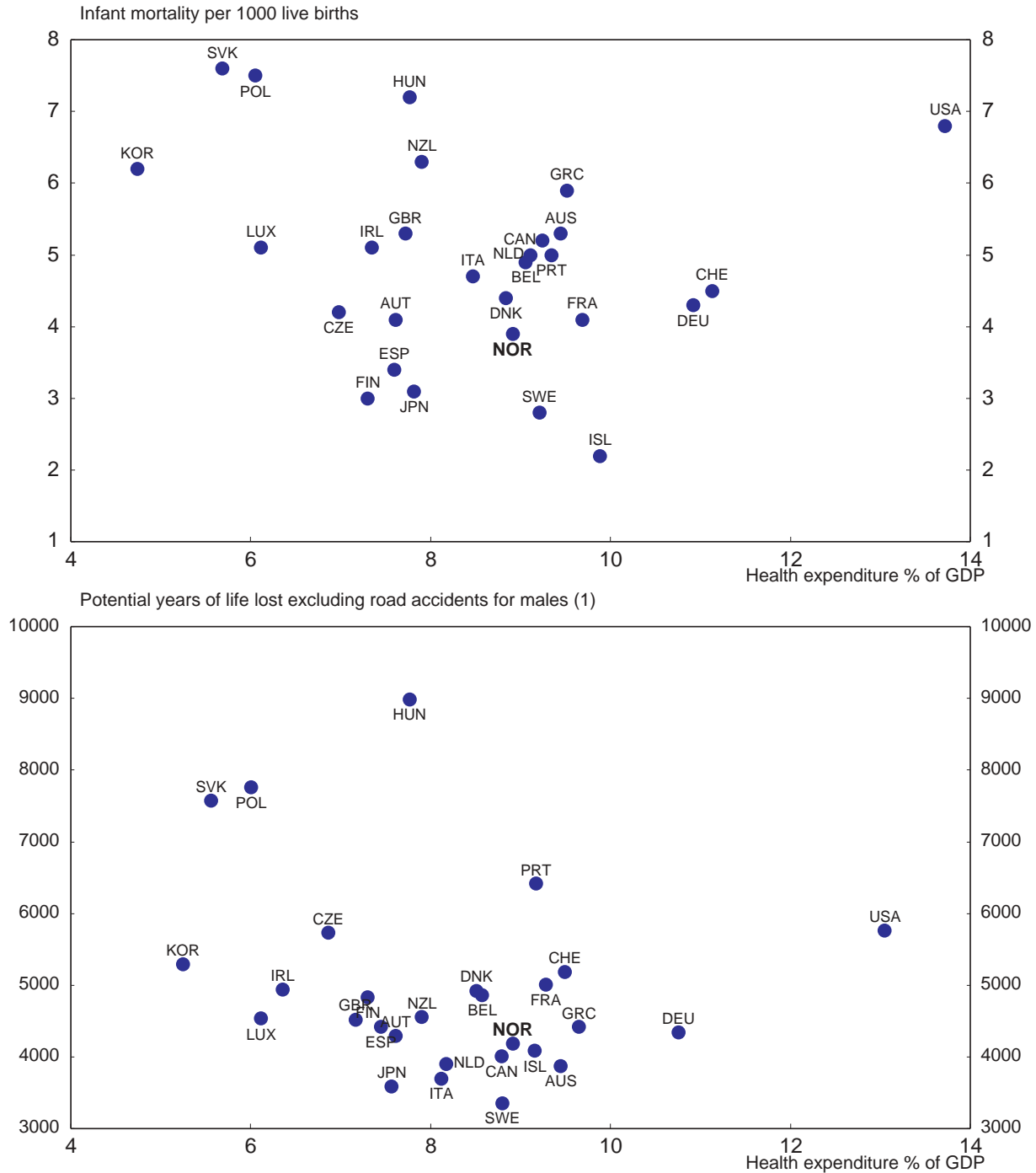

Note. No data available for Mexico and Turkey.

1. Males aged less than 70. The Potential Years of Life Lost is a summary measure of premature mortality which provides an explicit way of weighting deaths occuring at younger ages (before 70 years), which are a priori preventable. Rate per 100000.

Source: OECD Health Data, 2004. 
Figure A1.2. Health care personnel

Per 1000 population

In 2002 or latest year available ${ }^{1}$
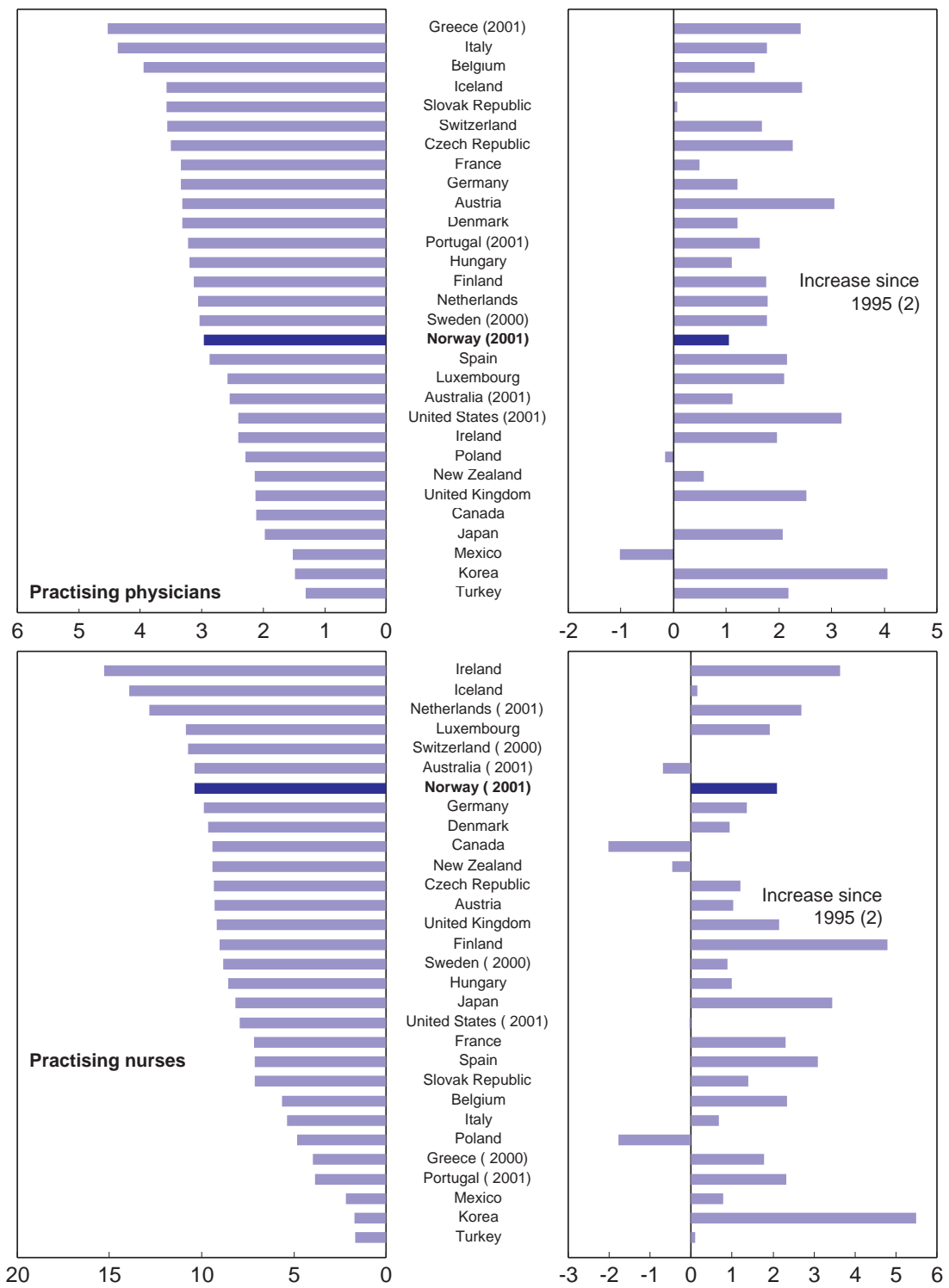

1. Shown into parenthesis.

2. Average annual percentage change since 1995 or nearest year available. For practising nurses, since 1997 for Norway, the Netherlands and Germany.

Source: OECD, Health Data 2004. 
Figure A1.3. Acute-care and long-term-care beds In 2002 or latest year available ${ }^{1}$
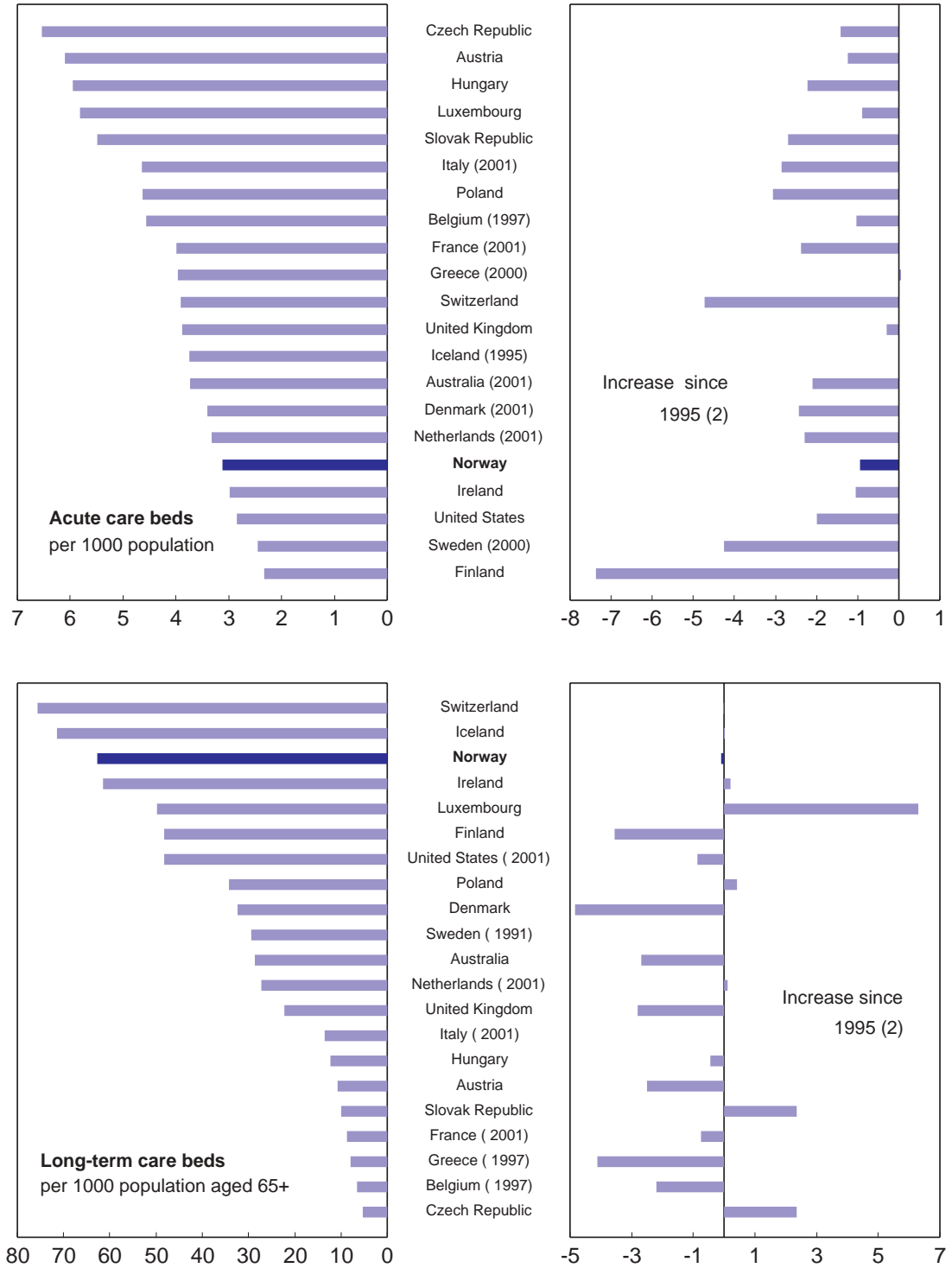

1. Shown into parenthesis.

2. Average annual percentage change (when available) since 1995 or nearest year available. Data available only from 1996 for the Slovak Republic. Only one observation in 2001 for Italy.

Source: OECD Health Data, 2004. 
Figure A1.4. Pharmaceutical expenditure

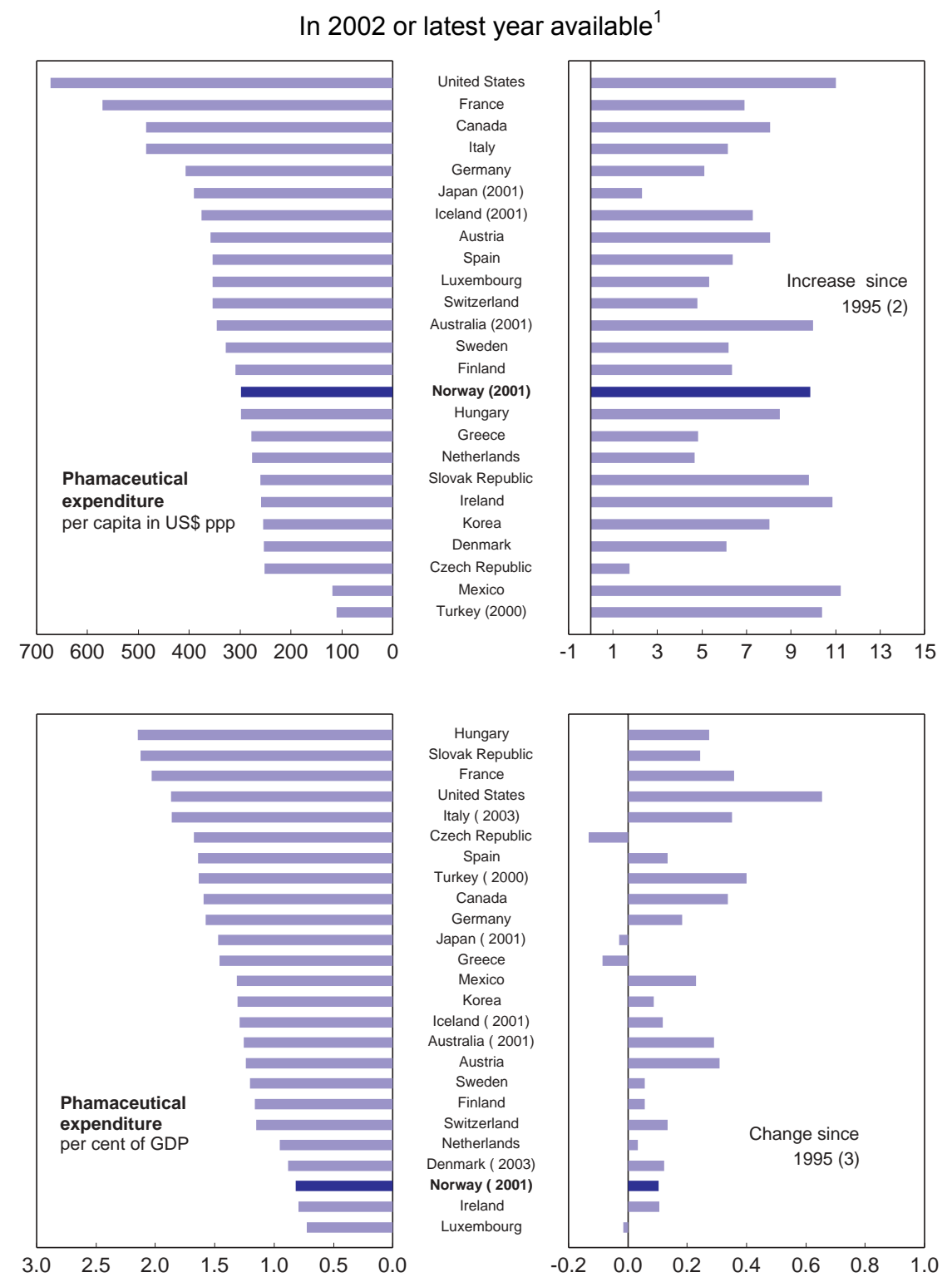

1. Shown in parenthesis.

2. Average annual percentage change (when available) since 1995 or nearest year available.

3. Change in level.

Source: OECD Health Data, 2004. 


\section{REFERENCES}

Askildsen, J. E., B.H. Baltagi and T.H. Holmas (2003), "Wage Policy in the Health Care Sector: A Panel Data Analysis of Nurses' Labour Supply", Health Economics, 12, 705-719.

Baltagi, B.H., E. Bratberg and Holmas (2003), “A Panel Data Study of Physicians' Labor Supply: The Case of Norway", CESifo Working Paper, No. 895.

Biorn, E., T.P. Hagen, T. Iversen and J. Magnussen (2003), "The Effect of Activity-Based Financing on Hospital Efficiency: A Panel Data Analysis of DEA Efficiency Scores 1992-2000”, Health care Management Science, 6, 271-283.

Board of Health (2002), Quality in Health Care, Report Series, 8/2002, Norwegian Board of Health, Oslo.

Board of Health (2004), "Norwegian Health and Social Services", www.helsetilsynet.no.

Board of Health (2004), "Summary of in The Wrong Place at the Right Time? Capacity in Departments of Internal Medicine. A Survey in 2002 and the Trend from 1999-2002”, www.helsetilsynet.no.

Board of Health (2004), "Summary of Still Not Enough Places: Capacity in Acute Departments of Psychiatry. A Survey in 2003 and the Trend from 2002-2003", www.helsetilsynet.no.

Board of Health (2004), "Summary of Dental Services in Norway. Supply of Public Dental Services to the Priority Groups, and the Dental Manpower Situation”, www.helsetilsynet.no.

Board of Health (2004), "Summary of Supervision of Specialist Health Services for Adults with Psychological Problems in 2003", www.helsetilsynet.no.

Board of Health (2004), "Summary of Supervision of Patients' Rights in Somatic Outpatient Clinics in 2003", www.helsetilsynet.no.

Brathaug, A. L. and E. Norgaard (2003), "The Cost of Inpatient Curative Care by Gender, Age and Diagnosis”, Economic Survey, 1/2003, Statistics Norway, Oslo.

Brekke, K. (2002), "Fra Forvaltning til Monopol i den Norske Sykehussektoren" ("From Administration to Monopoly in the Norwegian Hospital Sector"), Okonomisk Forum, 4, 13-19.

Carlsen, B. and O.F. Norheim (2003), "Introduction of the Patient-List System in General Practice. Changes in Norwegian Physicians' Perception of Their Gatekeeper Role", Scandinavian Journal of Primary Health Care, 21, 209-213.

Christensen, D.A. (2004), Deliverable D1: WP 1 - Country Report Norway, Active Ageing in Europe: Methods, Policies, and Institutions, The Activage Project.

Christensen, T., P. Laegreid and I.M. Stigen (2004), "Performance Management and Public Sector Reform: The Norwegian Hospital Reform", Paper presented at the EGPA conference Four Months After: 
Administering the New Europe - Study Group on Productivity and Quality in the Public Sector, Performance Measurement and Management in the Public Sector, Ljubljana, September 1-4, 2004.

Competition Authority (2004), Annual Report 2003. Competition Means Better and Cheaper Products, Norwegian Competition Authority, Oslo.

Docteur, E. and H. Oxley (2003), "Health-Care Systems: Lessons from the Reform Experience", Economics Department Working Paper, NO. 374, 05 Dec 2003, OECD, Economics Department, Paris.

van Doorslader, E. and C. Masseria (2004), "Income-Related Inequality in the Use of Medical Care in 21 OECD Countries", OECD Health Working Paper, No. 14, 11 May 2004, OECD, Directorate for Employment, Labour and Social Affairs, Paris.

ECON Centre for Economic Analysis (2000), Evaluation of the Reference Pricing System for Medicines. Prepared for the Ministry of Health and Social Affairs", Report 44/2000, available at www.lmi.no.

European Observatory on Health Care Systems (2000), Health Care Systems in Transition. Norway, European Observatory on Health Care Systems, Copenhagen.

Farmindustria (2004), Indicatori Farmaceutici, Farmindustria, Rome.

Grytten, J. and R. Sorensen (2004), "Primary Physician Services - List Size and Primary Physicians' service Production", mimeo.

Hagen, T.P. (2004), “The Norwegian Hospital reform of 2002”, Department of Health Management and Health Economics, University of Oslo, mimeo.

Hagen, T.P. and O. Kaarboe (2003), "Main Elements in NOU 2003:1 (The Hagen Commission Report). A PM to OECD's Norway/Italia Desk", mimeo.

Holmas, T.H. (2002), “Keeping Nurses at Work: A Duration Analysis”, Health Economics, 11, 493-503.

Hurst, J. and L. Siciliani (2003), "Tackling Excessive Waiting Times for Elective Surgery: A Comparison of Policies in Twelve OECD Countries", OECD Health Working Paper, No. 6, 07 July 2003, OECD, Directorate for Employment, Labour and Social Affairs, Paris.

Iversen, T. (2004), "The Effects of a Patient Shortage on General Practitioners' Future Income and List of Patients", Journal of Health Economics, 23, 673-694.

Iversen, T. (2005), "A study of income-motivated behavior among general practitioners in the Norwegian list patient system", University of Oslo Health Economics Research Programme, Working Paper 2005:8.

Iversen, T. and G.R. Kopperud (2003), "The Impact of Accessibility on the Use of Specialist Health Care in Norway", Health Care Management Science, 6, 249-261.

Iversen, T. and G.R. Kopperud (2005), "Regulation versus Practice. The Impact of Accessibility on the Use of Specialist Health care in Norway", Health Economics Research Programme, University of Oslo, Working Paper 2/2005. 
Kjerstad, E. (2003), "Prospective Funding of General Hospitals in Norway - Incentives for Higher Production?", International Journal of Health care Finance and Economics, 3, 231-251.

Lian, O.S. (2003), "Patient experiences in primary health care before and after the general pracititoners' reform”, ISM series of reports $\mathrm{N}^{\circ} 70 / 2003$, University of Tromsø, Institute of Medicine.

Lindbak, R. and B. I. Larsen (2003), “Tobacco Control in Norway”, Eurohealth, Volume 9, Number 2, Summer 2003, LSE Health and Social Care, London.

Ministry of Health (2004), Experiences on the Regular General Practitioner Scheme after Two and a Half Years - From the Implementation on June $1^{\text {st }} 2001$ to December $31^{\text {st }} 2003$. Summary, Ministry of Health, mimeo.

Ministry of Health (n.d.), "The Royal Norwegian Ministry of Health", http://odin.dep.no/hd/engelsk/ministry/about ministry/bu.html, accessed 3 August 2004.

Ministry of Health and Social Affairs (n.d.), "The Norwegian Hospital Reform - Central Government Assumes Responsibility for Hospitals", http://odin.dep.no/ordinarkiv/norsk/dep/shd/2001/eng/030071-990126/dok-nu.html, accessed 4 August 2004.

Ministry of Health and Social Affairs (n.d.), "The Regular GP Scheme Has Now Been Introduced", http://odin.dep.no/hd/engelsk/publ/veiledninger/030061-120010/dok-bu.html, accessed 3 August 2004.

Ministry of Social Affairs (2002), Prescriptions for a Healthier Norway. A Broad Policy for Public Health, Report No. 16 (2002-2003) to the Storting, Short Version, Ministry of Social Affairs, Oslo.

NOU 2005:3 (Norwegian Public Study 2005:3), "Fra Stykkevis Til Helt" ("From Pieces to Wholeness - A Report on Cooperation between Primary and Specialised Health Services"), Oslo.

OECD (1998), OECD Economic Survey of Norway, Paris.

OECD (1999), OECD Economic Survey of Norway, Paris.

OECD (2001), OECD Economic Survey of Norway, Paris.

OECD (2002), Lifelong Learning in Norway, Reviews of National Policies for Education, Paris.

OECD (2002), OECD Economic Survey of Norway, Paris.

OECD (2003), Norway: Preparing for the Future Now, OECD Reviews of Regulatory Reform, OECD, Paris.

OECD (2004), Towards High-Performing Health Systems, The OECD Health Project, OECD, Paris.

OECD (2004), OECD Economic Surveys. Norway, Volume 2004/6, OECD, Paris.

OECD (2004), Ageing and Employment Policies. Norway, OECD, Paris. 
Razzolini, T. (2004), "The Norwegian Market for Pharmaceuticals and the Non-Mandatory Substitution Reform of 2001: The Case of Enalapril”, Department of Economics Memorandum, No. 12/2004, June 2004, University of Oslo, Oslo.

Saether, E.M., 'Nurses' Labour Supply with Endogenous Choice of Care Level and Shift Type. A Discrete Choice Model with Nonlinear Income", HERO Working Paper, 2004:9, University of Oslo, Oslo.

Siciliani, L. and J. Hurst (2003), "Explaining Waiting Times Variations for Elective Surgery across OECD Countries", OECD Health Working Paper, No. 7, 07-Oct 2003, OECD, Directorate for Employment, Labour and Social Affairs, Paris.

Slattebrekk, O. V. and H. P. Aarseth (2003), "Aspects of Norwegian Hospital Reforms", Eurohealth, Volume 9, Number 2, Summer 2003, LSE Health and Social Care, London.

Statistics Norway (2002), Health Statistics 1992-2000, Statistics Norway, Oslo.

Statistics Norway (2004), "World Health Survey. A Survey on Health and Health System Responsiveness in Norway", www.ssb.no/english/subjects/03/00/whs_en/main.html. 


\section{WORKING PAPERS}

The full series of Economics Department Working Papers can be consulted at www.oecd.org/eco/Working_Papers/

478. How to sustain growth in a resource based economy? The main concepts and their application to the Russian case (February 2006) Rudiger Ahrend

477. Projecting OECD health and long-term care expenditures: What are the main drivers? (February 2006)

476. Alternative measures of well-being (January 2006) Romina Boarini, Åsa Johansson and Marco Mira D'Ercole

475. Recent house price developments: the role of fundamentals (January 2006) Nathalie Girouard, Mike Kennedy, Paul van den Noord and Christophe André

474. Reforming federal fiscal relations in Austria

(January 2006) Andrès Fuentes, Eckhard Wurzel and Andreas Wörgötter

473. Product market competition and economic performance in France

Concurrence sur les marchés de produits et performance économique en France

(January 2006) Jens Høj and Michael Wise

472. Product market reforms and employment in OECD countries

(December 2005) Giuseppe Nicoletti and Stefano Scarpetta

471. Fast-falling barriers and growing concentration: the emergence of a private economy in China (December 2005) Sean Dougherty and Richard Herd

470. Sustaining high growth through innovation: reforming the $R \& D$ and education systems in Korea (December 2005) Yongchun Baek and Randall Jones

469. The labour market in Korea: enhancing flexibility and raising participation (December 2005) Randall Jones

468. Getting the most out of public-sector decentralization in Korear (December 2005) Randall Jones and Tadashi Yokoyama

467. Coping with the inevitable adjustment in the US current account (December 2005) Peter Jarrett

466. Is there a case for sophisticated balanced-budget rules? (December 2005) Antonio Fatás

465. Fiscal rules for sub-central governments design and impact (December 2005) Douglas Sutherland, Robert Price and Isabelle Joumard

464. Assessing the robustness of demographic projections in OECD countries (December 2005) Frédéric Gonand

463. The Benefits of Liberalising Product Markets and Reducing Barriers to International Trade and Investment in the $O E C D$

(December 2005) 


\section{ECO/WKP(2006)9}

462. Fiscal relations across levels of government in the United States (November 2005) Thomas Laubach

461. Assessing the value of indicators of underlying inflation for monetary policy (November 2005) Pietro Catte and Torsten Sløk.

460. Regulation and economic performance: product market reforms and productivity in the OECD (November 2005) Giuseppe Nicoletti and Stefano Scarpetta.

459. Innovation in the Business Sector (November 2005) Florence Jaumotte and Nigel Pain

458. From Innovation Development to Implementation: Evidence from the Community Innovation Survey (November 2005) Florence Jaumotte and Nigel Pain

457. From Ideas to Development: the Determination of $R \& D$ and Patenting (November 2005) Florence Jaumotte and Nigel Pain

456. An Overview of Public Policies to Support Innovation (November 2005) Florence Jaumotte and Nigel Pain

455. Strengthening Regulation in Chile: The Case of Network Industries (November 2005) Alexander Galetovic and Luiz de Mello

454. Fostering Innovation in Chile (November 2005) José-Miguel Benavente, Luiz de Mello and Nanno Mulder

453. Getting the most out of public sector decentralisation in Mexico (October 2005) Isabelle Joumard

452. Raising Greece's Potential Output Growth (October 2005) Vassiliki Koutsogeorgopoulou and Helmut Ziegelschmidt

451. Product Market Competition and Economic Performance in Australia (October 2005) Helmut Ziegelschmidt, Vassiliki Koutsogeorgopoulou, Simen Bjornerud and Michael Wise

450. House Prices and Inflation in the Euro Area (October 2005) Boris Cournède

449. The EU's Single Market: At Your Service? (October 2005) Line Vogt

448. Slovakia's introduction of a flat tax as part of wider economic reforms (October 2005) Anne-Marie Brook and Willi Leibfritz

447. The Education Challenge in Mexico: Delivering Good Quality Education to All (October 2005) Stéphanie Guichard

446. In Search of Efficiency: Improving Health Care in Hungary (October 2005) Alessandro Goglio

445. Hungarian Innovation Policy: What's the Best Way Forward? (October 2005) Philip Hemmings

444. The Challenges of EMU Accession Faced by Catch-Up Countries: A Slovak Republic Case Study (September 2005) Anne-Marie Brook 